UNIVERSIDADE DE BRASÍLIA

INSTITUTO DE CIÊNCIA POLÍTICA E RELAÇÕES INTERNACIONAIS

DEPARTAMENTO DE RELAÇÕES INTERNACIONAIS

XII CURSO DE ESPECIALIZAÇÃO EM RELAÇÕES INTERNACIONAIS - 2010

\title{
A Cooperação Sul-Sul em Saúde - Análise Comparativa entre a atuação da CPLP e da UNASUL
}

Larissa Fernandes Nogueira da Gama

Orientadora: Prof. Dra. Maria Helena de Castro Santos

Monografia apresentada como requisito parcial para a obtenção do título de Especialista em Relações Internacionais pela Universidade de Brasília 
UNIVERSIDADE DE BRASÍLIA

INSTITUTO DE CIÊNCIA POLÍTICA E RELAÇÕES INTERNACIONAIS

DEPARTAMENTO DE RELAÇÕES INTERNACIONAIS

XII CURSO DE ESPECIALIZAÇÃO EM RELAÇÕES INTERNACIONAIS - 2010

A Cooperação Sul-Sul em Saúde - Análise Comparativa entre a atuação da CPLP e da UNASUL

Larissa Fernandes Nogueira da Gama

Orientadora: Prof. Dra. Maria Helena de Castro Santos

Brasília, 2011 
A responsabilidade pelo desenvolvimento do Sul compete ao Sul, $e$ está nas mãos das pessoas $e$ instituições do Sul.

Julius Nyere (1990) 


\title{
RESUMO
}

O presente trabalho apresenta, em um primeiro momento, a definição de um sistema de saúde, acentuando as suas características de hierarquização e regionalização. A seguir, contextualiza a cooperação internacional em saúde, ressaltando a recente mudança de paradigma da cooperação norte-sul para a cooperação sul-sul. Em seguida, expõe a maneira como a questão relativa à saúde vem sendo tratada no âmbito da Comunidade dos Países de Língua Portuguesa (CPLP) e no âmbito da União de Nações Sul-Americanas (UNASUL). E, ao final, realiza uma análise comparativa da atuação dos dois supracitados blocos, no que concerne ao incremento da atenção primária á saúde.

\begin{abstract}
This paper presents, at first, a health system definition, highlighting its features of hierarchy and regionalization. Following, puts health international cooperation in context, highlighting the recent paradigm shift in North-South cooperation towards South-South cooperation. Next, it points out how the matter of health has been treated within the Community of Portuguese Language Countries (CPLP) and within the Union of South American Nations (UNASUR). At last, it analyzes comparatively the performance of the two blocks above, regarding the increase in primary health care.
\end{abstract}


2 - SISTEMAS DE SAÚDE 9

2.1. CONCEITUAÇÃO E ClASSIFICAÇão dos Sistemas de SAÚde: 9

2.2. OS SISTEMAS DE SAÚDE MUNDIAIS: 12

2.2.1. CANADÁ: 12

2.2.2. ALEMANHA: 13

2.2.3. ESTADOS UNIDOS: 13

2.2.4. BRASIL: $\quad 14$

2.3. A ORGANIZAÇÃO DA OFERTA DAS AÇÕES E SERVIÇOS DE SAÚDE EM UM DETERMINADO SISTEMA DE SAÚDE: $\quad 15$

2.3.1. A IMPORTÂNCIA DA ATENÇÃO PRIMÁRIA À SAÚDE (APS): 20

2.4. OS GRANDES DESAFIOS A SEREM ENFRENTADOS PELOS SISTEMAS DE SAÚDE MUNDIAIS:

3 - A COOPERAÇÃO INTERNACIONAL:

3.1. A CONTEXTUALIZAÇÃO HISTÓRICA E A DEFINIÇÃO DA COOPERAÇÃO INTERNACIONAL:

3.2. ESPÉCIES DE COOPERAÇÃO INTERNACIONAL:

3.3. A COOPERAÇÃO INTERNACIONAL EM SAÚDE:

3.4. A MUDANÇA DE PARADIGMA NA COOPERAÇÃO INTERNACIONAL EM SAÚDE - DA COOPERAÇÃO NORTE-SUL PARA A COOPERAÇÃO SUL-SUL:

4 - A SAÚDE NO ÂMBITO DA COMUNIDADE DOS PAÍSES DE LÍNGUA PORTUGUESA (CPLP):

4.1. A Comunidade dos Países de Língua Portuguesa (CPLP):

4.2. A COOPERAÇÃO EM SAÚDE NO ÂMBITO DA CPLP - O PLANO ESTRATÉGICO DE COOPERAÇÃO EM SAÚDE (PECS/CPLP):

4.3. ANÁLISE CRÍTICA DO PECS/CPLP:

4.4. ANÁLISE DA EFICÁCIA DO PECS/CPLP NO QUE TANGE AO INCREMENTO DA ATENÇÃO PRIMÁRIA À SAÚDE NOS SISTEMAS DE SAÚDE DE SEUS PAÍSES MEMBROS:

5 - A SAÚDE NO ÂMBITO DA UNIÃO DAS NAÇÕES SUL-AMERICANAS (UNASUL)

5.1. A UNIÃO DAS NAÇÕES SUL-AMERICANAS (UNASUL):

5.2. A COOPERAÇÃO EM SAÚDE NO ÂMBITO DA UNASUL - O PLANO QUINQUENAL 2010/2015: 
5.4. ANÁLISE DA EFICÁCIA DO PLANO QUINQUENAL NO QUE TANGE AO INCREMENTO DA ATENÇÃO PRIMÁRIA À SAÚDE NOS SISTEMAS DE SAÚDE DE SEUS PAÍSES MEMBROS:

6 - CONCLUSÃO 54

REFERÊNCIAS BIBLIOGRÁFICAS 


\section{1 - INTRODUÇÃO}

A saúde, segunda preconiza a Organização Mundial de Saúde (OMS), pode ser definida como sendo a "situação de perfeito bem estar físico, mental e social da pessoa” (Segre; Ferraz, 1997:538). Por estar umbilicalmente ligada à qualidade de vida, constitui objetivo comum aos países da comunidade internacional a construção de sistemas de saúde que atendam a contento todos os seus cidadãos, uma vez que há um crescente consenso no sentido de que, sem populações saudáveis, não haverá desenvolvimento.

O presente trabalho visa apresentar a forma como a questão da cooperação internacional em matéria de saúde vem sendo tratada no âmbito da Comunidade dos Países de Língua Portuguesa (CPLP), assim como na União das Nações SulAmericanas (UNASUL), especificamente no que tange ao incremento da questão referente à Atenção Primária à Saúde ${ }^{1}$ (APS).

Dessa forma, inicialmente, será apresentada a conceituação de um sistema de saúde, assim como as suas espécies, expondo-se em seguir, em uma apertada análise, os sistemas de saúde adotados pelos países utilizados como paradigma na doutrina sanitária, entre eles o Brasil, premissa esta que se revela fundamental para a compreensão da controvérsia ora proposta.

Logo após, será explicitada a maneira como se organizam a oferta das ações e serviços de saúde dentro de um sistema de saúde, ocasião na qual restará conceituado o que vem a ser Atenção Primária à Saúde, critério escolhido como paradigma para a análise comparativa objeto do presente trabalho.

A seguir, no que tange à cooperação internacional em saúde, será contextualizada a sua evolução histórica, bem como apresentada as razões da alteração de paradigma da cooperação norte-sul para a cooperação sul-sul em matéria de saúde, assim como se demonstrará o recente fortalecimento da cooperação sul-sul,

\footnotetext{
${ }^{1}$ A conceituação do que vem a ser a atenção primária à saúde será apresentada no Capítulo 2, onde restará igualmente explicitada as razões de se ter adotado tal requisito como critério para a análise comparativa ora proposta.
} 
no âmbito da qual se situa o presente estudo, que restou focado na cooperação que vem sendo desenvolvida no âmbito da CPLP e da UNASUL.

E, ao final, será realizada uma análise comparativa do tratamento da questão da cooperação em saúde no âmbito dos dois supracitados blocos (CPLP e UNASUL), especificamente no que se refere à questão do fortalecimento da Atenção Primária à Saúde, crescimento este que, conforme se constará, revela-se essencial na construção de sistemas de saúde públicos de acesso universal eficazes. 


\section{2 - SISTEMAS DE SAÚDE}

\subsection{Conceituação e Classificação dos Sistemas de Saúde:}

A noção clássica de organização dos diversos serviços de saúde prestados a uma determinada população como sendo um sistema foi inicialmente concebida pelo médico britânico Bertrand Dawson, o qual, no início do século XX, propôs a reformulação do modelo de saúde britânico, de forma a compor um sistema de saúde, com base em diversos princípios (Rodrigues; Santos, 2009:47).

As supracitadas propostas foram todas reunidas no que se tornou conhecido como sendo o "Relatório Dawson”, inicialmente apresentado em 1920, cujas idéias se revelam fundamentais na organização do setor saúde como sistema, ou seja, como sendo um conjunto integrado de ações e serviços de saúde de caráter tanto preventivo como curativo, incluindo, ainda, a promoção e a educação para a saúde.

Os diversos sistemas de saúde mundiais se revelam como sendo o resultado de condicionantes históricas, bem como de decisões de cunho político tomadas pelos governos dos países da comunidade internacional no passado, assim como no presente (Pereira, M., 2008:515).

Atualmente, podemos constatar que existem diversas formas de organização dos sistemas de saúde no mundo, sendo uns públicos e dirigidos a todos, outros públicos ou semipúblicos, mas destinados a grupos determinados da população, bem como outros de natureza privada.

Assim, as diversas maneiras de se organizar um sistema de saúde podem ser classificadas, resumidamente, da maneira que segue abaixo (Rodrigues; Santos, 2009:15):

a) Sistema Público de Acesso Universal: nesta espécie de sistema de saúde, os serviços prestados podem ser utilizados de forma gratuita por qualquer cidadão, sem distinção alguma, sendo financiados mediante o pagamento de tributos, e administrados pelo Estado. A prestação dos serviços de saúde, neste sistema, cabe ao 
Poder Público (como regra geral), admitindo-se, em determinados casos, a sua prestação também por entidades privadas. Este sistema é adotado pelo Brasil, Canadá, Espanha, Austrália e Grã-Betanha, entre outros países.

b) Seguro Social: este sistema de saúde é estruturado tendo como destinatários grupos determinados de cidadãos, organizados segundo categorias profissionais, e geridos por institutos ou agências semipúblicas, administrados por representantes dos empregadores, dos trabalhadores e, às vezes, do próprio Estado. Este sistema é financiado por meio de contribuições obrigatórias, cobradas tanto dos empregadores quanto dos empregados. Assim, somente tem acesso aos serviços de saúde prestados os trabalhadores das categorias profissionais correspondentes, bem como seus dependentes. A prestação dos serviços de saúde, por sua vez, é feita tanto por estabelecimentos públicos quanto privados de saúde. Constitui o sistema de saúde adotado na Alemanha, França, Argentina e Japão; e

c) Saúde Privada: este sistema é direcionado para as pessoas que pagam pelos serviços prestados, ou então àquelas que contratam planos ou seguros de saúde. Assim, este sistema é financiado diretamente pelos seus usuários (aqueles que contratam os planos ou seguros de saúde), bem como pelas empresas que os empregam. A administração destes sistemas é realizada de forma privada, muitas vezes havendo a regulação da matéria pelo Estado. A prestação dos serviços de saúde, como regra geral, é feita por estabelecimentos privados. Este sistema de saúde foi o adotado pelos Estados Unidos, Suíça e Nova Zelândia.

Estes são os três principais sistemas de saúde, segundo a classificação adotada pela doutrina sanitarista, embora deva ser ressaltada a circunstância de que os sistemas de saúde de inúmeros países revelam-se mistos, ou seja, nestes casos verifica-se a combinação de aspectos dos três sistemas ora apresentados.

Como regra geral, revela-se válida a adoção da premissa segundo a qual a maior parte dos países desenvolvidos assegura à totalidade (ou à maior parte de seus 
cidadãos) o acesso aos serviços de saúde, seja por meio dos sistemas públicos de caráter universal, seja sob a modalidade do seguro social obrigatório. ${ }^{2}$

Para a devida compreensão dos sistemas de saúde, apresenta-se o quadro exposto abaixo, elaborado segundo os critérios da forma e condição de acesso, forma de financiamento, organização, prestação dos serviços e países adotantes (Rodrigues; Santos, 2009:16):

\begin{tabular}{|c|c|c|c|c|c|}
\hline Sistemas & Acesso & $\begin{array}{c}\text { Condição } \\
\text { para o } \\
\text { Acesso }\end{array}$ & Organização & $\begin{array}{c}\text { Forma de } \\
\text { Financiamento }\end{array}$ & Países \\
\hline $\begin{array}{c}\text { Público de } \\
\text { Acesso } \\
\text { Universal }\end{array}$ & Universal & $\begin{array}{l}\text { Direito de } \\
\text { Cidadania }\end{array}$ & Pública & Tributos & $\begin{array}{c}\text { Brasil, } \\
\text { Canadá, } \\
\text { Espanha, } \\
\text { Suécia, } \\
\text { Reino Unido } \\
\text { e Itália }\end{array}$ \\
\hline $\begin{array}{l}\text { Seguro } \\
\text { Social }\end{array}$ & $\begin{array}{l}\text { Múltiplo, de } \\
\text { acordo com as } \\
\text { categorias } \\
\text { profissionais }\end{array}$ & $\begin{array}{c}\text { Benefícios } \\
\text { segundo as } \\
\text { contribuições } \\
\text { pagas }\end{array}$ & Semipública & $\begin{array}{c}\text { Contribuições } \\
\text { sobre a folha de } \\
\text { pagamento }\end{array}$ & $\begin{array}{c}\text { Alemanha, } \\
\text { França, } \\
\text { Argentina e } \\
\text { Japão }\end{array}$ \\
\hline Privado & Individual & $\begin{array}{c}\text { Pagamento } \\
\text { pelo serviço } \\
\text { prestado }\end{array}$ & Privada & Privada & $\begin{array}{c}\text { Estados } \\
\text { Unidos, } \\
\text { Nova } \\
\text { Zeilândia e } \\
\text { Suíça }\end{array}$ \\
\hline
\end{tabular}

2 Aqui revela-se mais precisa a utilização da palavra "cidadão", e não habitante, uma vez que o acesso aos sistemas de saúde, na maior parte dos casos, somente á assegurado ao cidadão de um determinado país, e não ao estrangeiro, embora alguns assegurem o pleno acesso ao estrangeiro residente, como ocorre no Brasil. 
Uma vez apresentada a definição do que seja um serviço de saúde, bem como explicitada a sua classificação, serão abaixo delimitados, em apertada síntese, os sistemas de saúde utilizados como referência na doutrina sanitária, para a devida compreensão da controvérsia objeto do presente trabalho.

\subsection{Os Sistemas de Saúde Mundiais:}

Ainda segundo Rodrigues et Santos (2009), os sistemas de saúde adotados como paradigma na doutrina sanitária possuem as seguintes características, verbis:

\subsubsection{Canadá:}

O Canadá adotou o sistema de saúde público de acesso universal.

Desde o ano de 1966, o sistema de saúde canadense tornou-se efetivamente público e de acesso universal, passando a oferecer cobertura completa (a todos os seus cidadãos) no que tange às ações e serviços de saúde.

Neste país, o controle estatal sobre a questão da saúde é quase total, sendo que o Ministério da Saúde canadense controla, inclusive, o número de vagas em cursos de medicina, bem como os relativos às especialidades médicas.

O sistema de saúde construído pelo estado canadense encontra-se estruturado na figura dos médicos de família, os quais possuem formação generalista, representado a principal porta de entrada deste sistema de saúde, uma vez que eles controlam o acesso dos usuários aos exames de diagnóstico e à maior parte dos médicos especialistas.

O financiamento do sistema de saúde canadense ocorre com base em tributos estatais, de maneira compartilhada entre os governos federais, provinciais e territoriais. 
No entanto, apesar do sistema adotado no Canadá ser o público de acesso universal, os serviços de saúde são prestados de forma privada, embora a quase totalidade dos profissionais de saúde do país trabalhem para o governo canadense, embora com uma certa independência.

\subsubsection{Alemanha:}

O sistema de saúde adotado pela Alemanha é o do seguro social.

A Alemanha estruturou seu sistema de saúde através da legislação social instituída no governo de Otto von Bismark, entre 1883 e 1889.

Desde então, os serviços de saúde são organizados por diversos fundos, correspondentes às categorias profissionais nas quais se divide a massa trabalhadora alemã, sendo dirigidos por representantes dos empregadores e dos trabalhadores de cada uma destas categorias.

Com exceção de alterações pontuais, o sistema de saúde alemão se mantém o mesmo desde a sua criação, embora se verifique, desde a década de 1970, um aumento considerável em seus custos, circunstância esta que se revelou como sendo um dos maiores entraves ao pleno desenvolvimento da saúde neste país.

Além dos crescentes custos, outro grande entrave ao sistema de saúde alemão reside no fato de que, por ser extremamente fragmentado, as suas partes não conseguem atuar de forma coordenada. Há, ainda, uma nítida separação entre o atendimento ambulatorial e o hospitalar, o que fragiliza ainda mais o sistema.

\subsubsection{Estados Unidos:}

O sistema de saúde norte-americano é eminentemente privado.

Somente no curso da década de 60, foram criados os dois grandes programas públicos de saúde americanos, quais sejam o Medicaid (destinado à parcela mais 
pobre da população americana) e o Medicare (dirigido aos americanos com idade igual ou superior a sessenta anos), de forma que, da maneira como se encontra atualmente estruturado o sistema americano, apenas os cidadãos mais pobres, assim como os idosos, possuem direito de acesso ao sistema público de saúde, dependendo, todos os demais, do setor privado.

Dessa forma, a predominância do sistema privado de saúde, bem como o nítido caráter residual dos sistemas públicos implementados - o Medicaid e o Medicare, trazem como conseqüência o fato de que uma parcela expressiva da população norte-americana não possui direito a nenhuma cobertura pública de serviços de saúde.

Outra característica marcante do sistema de saúde dos EUA reside na presença maciça e dominante das empresas privadas de seguro de saúde, as quais exercem enorme influência sobre os estabelecimentos hospitalares, médicos e profissionais de saúde.

Em virtude de todas estas circunstâncias, a defesa da implantação de um sistema público de saúde mais abrangente tem sido uma grande bandeira de luta dos mais diversos setores da população norte-americana, assim como de organizações não governamentais.

\subsubsection{Brasil:}

O Brasil adotou o modelo de sistema de saúde público de acesso universal, reservando nossa Constituição uma Seção específica para tratar da saúde. ${ }^{3}$

O artigo 196 da Constituição Federal revela a adoção do sistema público de acesso universal à saúde, ao dispor que "a saúde é direito de todos e dever do Estado, garantido mediante políticas sociais e econômicas que visem a redução do risco de doença e de outros agravos e ao acesso universal e igualitário às ações e serviços para a sua promoção, proteção e recuperação".

\footnotetext{
${ }^{3}$ Na constituição Brasileira de 1988, a saúde foi reconhecida como sendo um direito social (em seu artigo 6ㅇ), tendo sido a ela reservada, ainda, uma Seção específica, no âmbito de seu Título VIII, que dispõe acerca da Ordem Social. Assim, a saúde em nosso Estado restou delineada nos artigos 196 a 200 da Magna Carta.
} 
Nesse contexto, o artigo 198 da Carta Magna prevê que "as ações e serviços públicos de saúde integram uma rede regionalizada e hierarquizada e constituem um sistema único”, ou seja, o Sistema Único de Saúde (SUS).

Ainda segundo o artigo 198 da Constituição Federal, o SUS deve ser organizado segundo as seguintes diretrizes: (i) descentralização, com direção única em cada esfera de governo; (ii) atendimento integral, com prioridade para as atividades preventivas, sem prejuízo dos serviços assistenciais; e (iii) participação da comunidade.

Em relação ao financiamento do SUS, o $§ 1^{\circ}$ do art. 198 da Carta Magna estipula que “o sistema único de saúde será financiado com recursos do orçamento da seguridade social, da União, dos Estados, do Distrito Federal e dos Municípios, além de outras fontes.” Ou seja, a responsabilidade pelo financiamento do SUS fica a cargo das três esferas de gestão (federal, estadual e municipal).

E, por fim, a Constituição Federal dispôs, ainda, em seu artigo 199, que "as instituições privadas poderão participar de forma complementar ao sistema único de saúde, segundo diretrizes deste, mediante contrato de direito público ou convênio, tendo preferência as entidades filantrópicas e as sem fins lucrativos”.

\subsection{A organização da oferta das ações e serviços de saúde em um determinado Sistema de Saúde:}

As ações e serviços de saúde prestados por um determinado sistema de saúde visam, precipuamente, evitar o surgimento de doenças, ou, caso elas já existam, deter ou modificar o seu curso, tanto em nível individual quanto coletivo.

Através da utilização das mais diversas técnicas de planejamento, os gestores de um sistema de saúde procuram organizar a oferta dos serviços de saúde a serem prestados, bem como orientar suas ações no sentido de satisfazer a sociedade da melhor forma possível. 
Para que se atinja a necessária racionalização na disposição destes serviços à população, a doutrina sanitarista recomenda o ordenamento hierarquizado destes serviços, em três níveis distintos de complexidade, com o objetivo de facilitar o acesso da população aos diversos tipos de serviços de saúde prestados (Pereira, M., 2008:517).

Nesse contexto, a representação mais conhecida do ordenamento dos serviços de saúde em um determinado sistema tem a forma de uma pirâmide, na qual as ações e serviços disponíveis encontram-se agrupadas, em um nível de complexidade crescente, em atenção primária, atenção secundária e atenção terciária à saúde, na forma como consta ilustrado abaixo:

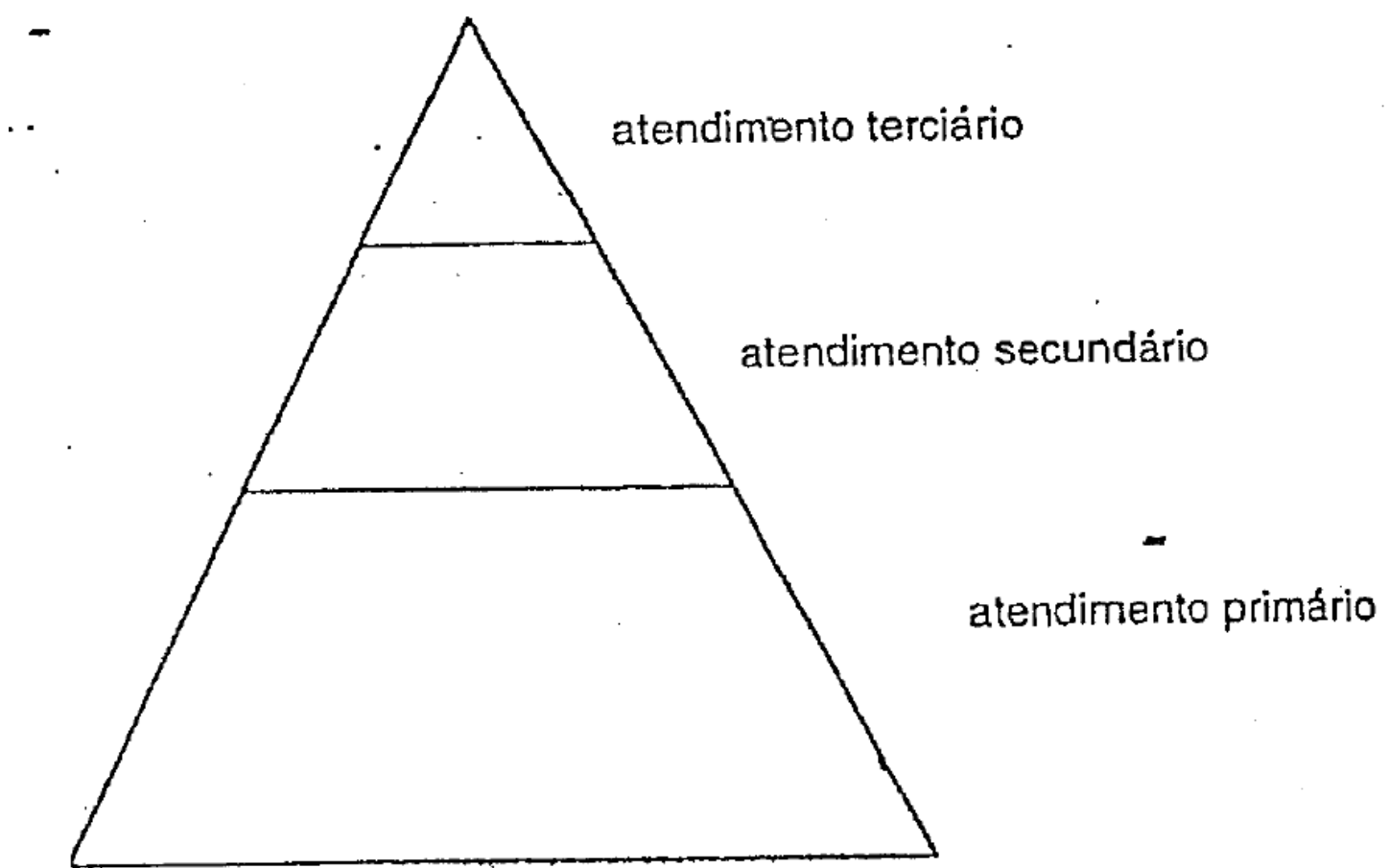

In: Pereira, M., 2008:517

Como se percebe, na base da pirâmide encontra-se a atenção primária à saúde, composta pelas ações e serviços de saúde mais simples, os quais, devido à sua pouca complexidade, são comumente ofertados à população em postos ou centros de saúde, pequenos ambulatórios e consultórios aptos a atender aos agravos mais freqüentes. 
A atenção primária à saúde foi definida pela Organização Mundial da Saúde, no âmbito da Declaração de Alma-Ata ${ }^{4}$, como sendo, verbis:

Atenção essencial à saúde baseada em tecnologia e métodos práticos, cientificamente comprovados e socialmente aceitáveis, tornados universalmente acessíveis a indivíduos e famílias na comunidade por meios aceitáveis para eles e a um custo que tanto a comunidade como o país possa arcar em cada estágio de seu desenvolvimento, um espírito de autoconfiança e autodeterminação. É parte integral do sistema de saúde de um país, do qual é função central, sendo o enfoque principal do desenvolvimento social e econômico global da comunidade. É o primeiro nível de contato dos indivíduos, da família e da comunidade com o sistema nacional de saúde, levando a atenção à saúde o mais próximo possível do local onde as pessoas vivem e trabalham, constituindo o primeiro elemento de um processo de atenção continuada à saúde.

O atendimento primário à saúde presta os serviços de saúde mais elementares, ou seja, os “cuidados primários de saúde”, constituindo, desta forma, a porta de entrada de um usuário em um determinado sistema de saúde, com ele estabelecendo o seu primeiro contato.

Inclusive, a atenção primária à saúde, por englobar, na maioria dos casos, problemas de natureza de saúde mais simples, pode vir a ser prestada sem a participação direta de médicos ou outros profissionais de nível superior, desde que o sistema conte com profissionais de nível técnico devidamente capacitados para o atendimento à população (Pereira, M., 2008:517).

Ocupando uma posição intermediária, encontra-se o atendimento secundário à saúde, no âmbito do qual são ofertadas serviços de saúde mais complexos, os quais devem ser necessariamente manejados por médicos e profissionais de saúde de nível superior.

\footnotetext{
4 A Declaração de Alma-Ata pode ser acessada no endereço eletrônico da Organização PanAmericana da Saúde http://www.opas.org.br/coletiva/uploadArq/Alma-Ata.pdf. Acesso em 03/03/2011.
} 
Tais serviços são comumente prestados em clínicas ou hospitais de médio porte, e servem, ainda, de complementação aos serviços primários de saúde, caso estes não sejam suficientes para combater a contento um determinado agravo.

E, por último, no topo da pirâmide, encontra-se a atenção terciária à saúde, na qual se inserem os hospitais de grande porte, responsáveis pelo atendimento às doenças mais complexas, concentrando, desta forma, o que existe de mais especializado no sistema em termos tanto de atendimento quanto de pessoal qualificado.

Segundo esta estrutura piramidal, os hospitais exercem a função principal na atenção secundária e terciária, mas apenas uma função de apoio na atenção primária. E, além disso, esta estrutura em forma de pirâmide confere uma noção exata de volume e importância dos três níveis de atenção à saúde, na medida em que prevê um grande volume de serviços primários, alguns secundários e um quantitativo mínimo de serviços terciários.

Esta representação confere com a realidade cotidiana dos sistemas de saúde, na medida em que estima-se que $90 \%$ (noventa por cento) das doenças que demandam os serviços de um sistema de saúde podem ser resolvidas na atenção primária; 8\% (oito por cento) na atenção secundária e somente 2\% (dois por cento) das doenças chegam a acionar a atenção terciária à saúde (Ibid.).

A par da hieraquização de um sistema de saúde, com a sua divisão em atenção primária, secundária e terciária à saúde, outro aspecto que merece destaque é a sua regionalização, que diz respeito à organização espacial dos serviços prestados, e que deve ser feita levando-se em conta as condições geográficas de um determinado país.

A regionalização, desta forma, constitui uma diretriz segundo a qual, a partir da delimitação geográfica de um sistema de saúde, objetiva-se a racionalização na prestação dos serviços de saúde, através da descentralização da tomada de decisões, bem como da hierarquização das ações, segundo a sua complexidade (Pereira, M., 2008:518). 
Nesse contexto, as pequenas estruturas de serviços de saúde (os postos e os centros de saúde, responsáveis pela atenção primária à saúde), ficam responsáveis pela prestação dos cuidados gerais, assim como pelos serviços básicos de saúde à população de uma determinada área geográfica do sistema. Caso tais estruturas revelem-se inaptas para atender a um determinado usuário, eles serão encaminhados aos hospitais secundários (responsáveis pela atenção secundária à saúde), e caso ainda assim seja necessário, este usuário será encaminhado ao hospital terciário, responsável pelo atendimento dos casos mais complexos, e que, naturalmente, será responsável pela cobertura de uma área miais extensa de um determinado sistema de saúde, na maneira como proposta na figura abaixo (Ibid.):

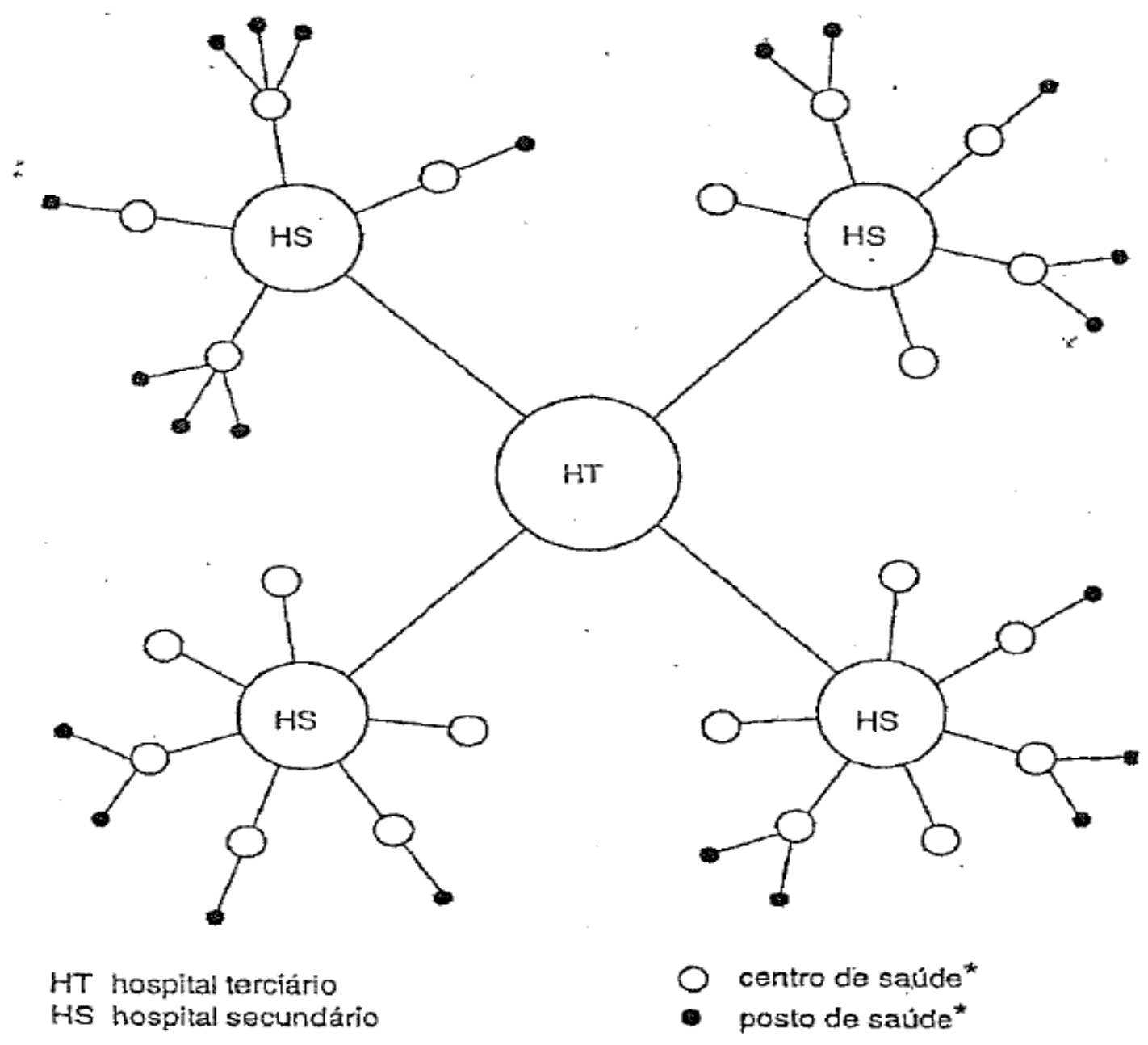

In: Pereira, M., 2008:518 
A figura exposta acima traduz uma estrutura consensualmente aceita no âmbito da doutrina sanitarista, pois racionaliza o atendimento, assim como minimiza os efeitos do custo crescente do setor saúde, uma vez que os serviços de saúde ficam estrategicamente dispostos em pontos geográficos previamente determinados, evitando a duplicação de esforços, mas satisfazendo as necessidades de uma determinada população, em termos de assistência à saúde (Ibid.)

É importante ressaltar, ainda, que a proporção entre os tipos de serviços de saúde a serem prestados e a população a ser atendida é quantificado com base em estudos específicos, podendo-se estabelecer, contudo, em termos gerais, como sendo necessário um hospital terciário para uma grande região ou populações de um milhão ou mais de habitantes; um hospital secundário para populações entre cinqüenta e quinhentos mil habitantes, bem como centros de saúde para grupos de população entre cinco mil e cinqüenta mil pessoas. Por sua vez, os postos de saúde devem ser considerados como sendo satélites dos centros, destinados a atender populações específicas e reduzidas, não dispondo, em caráter permanente, de profissionais de saúde de nível superior (Ibid.).

\subsubsection{A importância da Atenção Primária à Saúde (APS):}

Como visto, a atenção primária à saúde representa a porta de entrada do usuário em um sistema de saúde, o seu primeiro contato com este sistema, normalmente feito em postos ou centros de saúde - sendo suficiente, segundo o já afirmado, para resolver aproximadamente 90\% (noventa por cento) da demanda de um determinado sistema de saúde.

Após dar entrada em um sistema, o usuário é inicialmente avaliado (e mesmo tratado) no âmbito da atenção primária à saúde. Caso esteja acometido de um agravo de maior complexidade, ele será encaminhado, pela estrutura administrativa da atenção primária, ao nível secundário ou terciário do sistema. 
Nesse contexto, percebe-se facilmente a importância e a relevância da atenção primária à saúde, notadamente nos sistemas de saúde de acesso universal, uma vez que ela não somente resolve a grande maioria dos agravos, mas também encaminha os usuários aos níveis secundários e terciários do sistema, nos casos em que sejam constatadas doenças que necessitem de tratamento mais complexo.

Assim, especificamente nos sistemas de saúde de acesso universal, constatase facilmente que uma atenção primária à saúde precariamente estruturada desestabiliza todo o sistema, uma vez que, além de não responder a contento pela grande maioria dos casos que nele dão entrada, prejudica igualmente o acesso dos usuários as níveis superiores, nos quais se encontram os tratamentos mais complexos.

Isso ocorre, por exemplo, no Brasil, uma vez que ainda hoje a atenção primária do sistema de saúde brasileira revela-se mal estruturada, não sendo raro a notícia, nos meios de imprensa brasileiro, da precariedade de atendimento nos postos e centros de saúde, o que gera, por conseqüência natural, a superlotação dos hospitais públicos, para onde acabam se dirigindo milhares de usuários que poderiam ter sido atendidos a contento na atenção primária (mas não foram), circunstância esta que acaba prejudicando, por consequência, a prestação dos serviços de saúde nas atenções secundárias e terciárias.

Caso o Brasil contasse com uma atenção primária à saúde melhor estruturada, o caos que aflige hoje os hospitais públicos seria drasticamente reduzido (ou quem sabe até mesmo eliminado), uma vez que uma parcela significativa da população que a eles se dirige hoje seria atendida eficazmente em postos ou centros de saúde, possibilitando, dessa forma, que os serviços oferecidos pelos hospitais públicos fossem prestados somente a quem deles realmente necessitasse.

Assim, pela relevância do papel exercido pela atenção primária em um sistema de saúde, este foi o critério escolhido para a análise comparativa a qual se propõe o presente trabalho, que apresentará a forma como a questão da atenção primária à saúde vem sendo tratada no âmbito da Comunidade dos Países de Língua Portuguesa (CPLP), bem como no âmbito da União das Nações Sul-Americanas (UNASUL). 


\subsection{Os grandes desafios a serem enfrentados pelos sistemas de saúde mundiais:}

A primeira constatação que se verifica, em relação aos sistemas de saúde dos diversos países da comunidade internacional, é a de que existem desigualdades incomensuráveis entre eles, razão pela qual podemos concluir que o "direito à saúde para todos” que fundamentou a criação da OMS em 1948 encontra-se ainda muito distante de ser efetivamente atingido pela comunidade internacional (Bulard, 2010).

Com efeito, os trinta países da Organização de Cooperação e de Desenvolvimento Econômico (OCDE $)^{5}$ detentores das maiores taxas de natalidade concentram nada menos do que $90 \%$ (noventa por cento) das despesas mundiais com saúde, embora contem com apenas $20 \%$ (vinte por cento) da população mundial (Ibid.).

A África subsaariana, a qual conta com $12 \%$ (doze por cento) da população mundial, emprega menos de $1 \%$ (um por cento) de seus gastos no setor saúde, enquanto os gastos com saúde superam 8\% (oito por cento) do PIB no Japão, e 11\% (onze por cento) na França (Ibid.).

Nesse contexto, percebe-se facilmente a importância da cooperação internacional em saúde, uma vez que ela seria um instrumento hábil, desde que bem utilizada, para diminuir os gigantescos abismos existentes entre os diversos sistemas de saúde mundiais, notadamente no que tange os países africanos (cujos sistemas ainda se revelam precariamente estruturados), sobretudo no que tange à atenção primária à saúde.

\footnotetext{
${ }^{5}$ A Organização para a Cooperação e o Desenvolvimento Econômico (OCDE) foi criada em 1961, contando, atualmente, com 30 países da Europa, América do Norte, Ásia e Oceania. Encontra-se estruturada em diversos Diretórios, que se subdividem em Comitês, os quais atuam, principalmente, nas áreas sociais e econômicas.
} 


\section{3 - A COOPERAÇÃO INTERNACIONAL:}

\subsection{A contextualização histórica e a definição da Cooperação Internacional:}

Apesar de não ser possível identificar precisamente o momento do surgimento do fenômeno da cooperação internacional, a maioria da doutrina internacionalista é unânime no sentido de apontar que o período pós-guerra constitui um marco no desenvolvimento, assim como no fortalecimento do instituto da cooperação internacional (Silvestre, 2007:35).

Tal marco é compreensível no sentido de que, efetivamente, a Europa foi devastada por duas guerras em larga escala, sendo natural que, após 1945, tenha surgido um contexto fático favorável a uma maior cooperação entre as nações então existentes, no sentido de superarem, conjuntamente, as conseqüências destas duas grandes batalhas.

Assim, desde o fim da Segunda Guerra Mundial a cooperação internacional tem se constituído como sendo uma importante ferramenta para a promoção das relações internacionais, bem como em um importante fator de apoio ao desenvolvimento mundial.

Nesse contexto, desde a segunda metade da década de 1940, a cooperação internacional vem sendo largamente utilizada, tendo tido como objetivo inicial a reconstrução dos territórios devastados pelas guerras, dando-se origem, assim, a que comumente se denomina como sendo a "cooperação para o desenvolvimento", ocasião na qual se assentou o entendimento de que a cooperação internacional cumpriria um papel essencial na efetivação de políticas de desenvolvimento. (Ibid.)

Além disso, a criação da Organização das Nações Unidas (ONU), em 1948, constitui outro grande marco no desenvolvimento da cooperação internacional, na medida em que a sua criação acarretou, naturalmente, uma maior dinâmica nas 
relações internacionais, uma vez que a própria ONU se colocou como sendo um dos maiores atores de cooperação internacional.

Usualmente, a expressão “cooperação internacional” tem sido utilizada como indicativa de uma modalidade de relação entre países, podendo ser estabelecida tendo-se em vista os mais diversos objetivos; ou, ainda, para designar uma relação entre atores de países distintos, envolvendo doações, empréstimos, ajuda humanitária ou outras atividades.

Assim, a cooperação internacional pode ser definida como sendo o conjunto de atuações de caráter internacional, destinadas ao intercâmbio de experiências e recursos entre países, ou entre atores de países diferentes, com o objetivo de se atingir metas comuns, previamente estabelecidas, baseadas nos critérios de solidariedade, igualdade, eficácia, interesse mútuo, sustentabilidade e coresponsabilidade.

Como regra geral, á válido afirmar que a cooperação internacional tem sido utilizada como sendo um meio para a solução de questões que assolam a comunidade internacional como um todo, tais como problemas de caráter sociais, humanitários, econômicos ou culturais, bem como para estimular o respeito aos direitos humanos fundamentais.

Tais aspectos revelam-se presentes no artigo $1^{\circ}$, alínea 3, da Carta de São Francisco $^{6}$, o qual determina, verbis:

$$
\begin{aligned}
& \text { Conseguir uma cooperação internacional para resolver os } \\
& \text { problemas internacionais de caráter econômico, social, cultural ou } \\
& \text { humanitário, e para promover e estimular o respeito aos direitos } \\
& \text { humanos e às liberdades fundamentais para todos, sem distinção de } \\
& \text { raça, sexo, língua ou religião. }
\end{aligned}
$$

Desta forma, a cooperação internacional possui como objetivos, entre outros: a erradicação da pobreza, do desemprego e da exclusão social, a busca do desenvolvimento sustentável, assim como o aumento permanente nos níveis de

\footnotetext{
${ }^{6}$ A Carta de São Francisco dispõe acerca dos princípios e dos propósitos da Organização das Nações Unidas (ONU), podendo ser acessada no endereço eletrônico <http://www.onubrasil.org.br/doc1.php>. Acesso em 02/03/2011.
} 
desenvolvimento político, econômico, social e cultural dos países envolvidos (Silvestre, 2007:37 apud SEGIB).

No Brasil, a cooperação internacional tem sido largamente utilizada, sendo que, em 1987 foi criado, no âmbito do Ministério das Relações Exteriores (MRE), a Agência Brasileira de Cooperação (ABC), cuja função precípua consiste em desempenhar o papel de órgão central do sistema de cooperação técnica internacional do Brasil.

\subsection{Espécies de Cooperação Internacional:}

A Doutrina das Relações Internacionais não é rígida no que tange à definição dos tipos de cooperação internacional, adotando critérios diversos nesta classificação, notadamente devido à circunstância de que este instituto ainda não foi plenamente elaborado no nível teórico, uma vez que se trata de fenômeno que ainda vem sendo objeto de construção teórica.

Entre os diferentes critérios utilizados para a classificação da cooperação internacional, podemos destacar os relativos à origem da ajuda (segundo o qual a cooperação internacional pode ser pública ou privada), o que diz respeito ao caráter do fundo envolvido (e, aqui, a cooperação internacional pode ser reembolsável ou não reembolsável), ou ainda o critério relativo aos objetivos da cooperação internacional (para o desenvolvimento, para a saúde, o meio ambiente, a luta contra a pobreza, entre tantos outros) (Silvestre, 2007:38).

A classificação mais largamente utilizada utiliza como critério o tipo de ator envolvido na cooperação, e divide a cooperação internacional em bilateral, multilateral e não governamental. 
A cooperação internacional bilateral á aquela realizada entre dois países, concretizando-se através de “Convênios Básicos de Cooperação Técnica”, os quais regulam as condições, o objetivo, o alcance e as áreas a serem atendidas ${ }^{7}$.

Por sua vez, a cooperação multilateral constitui a cooperação que ocorre entre diversos países através da intermediação das Organizações Internacionais, as quais ficam responsáveis pela sua organização e execução.

E, por fim, a cooperação internacional não governamental constitui uma relação de parceria entre fundações e instituições não-governamentais de diferentes países.

De qualquer maneira, não havendo um único critério para a classificação dos tipos de cooperação internacional, revela-se mais produtivo a identificação, a partir de um determinado caso concreto, o sistema classificatório que melhor atenda às suas especificidades (Ibid.).

\subsection{A Cooperação Internacional em Saúde:}

As ações internacionais relativas ao setor saúde remontam à Idade Média, ocasião na qual foram estabelecidos, na Europa, os primeiros cordões sanitários e quarentenas marítimas, com o objetivo de se evitar a propagação de doenças, uma vez que a medicina da época ainda não se revelava capaz de combatê-las prontamente (Silvestre, 2007:42).

No entanto, foram as epidemias de cólera, as quais invadiram a Europa e os Estados Unidos ao longo do século XIX, as responsáveis pela percepção das elites da época acerca da relevância dos problemas sanitários, quando então se percebeu a necessidade de combate às doenças na esfera internacional, contexto que possibilitou

\footnotetext{
${ }^{7}$ Em relação à cooperação bilateral, esta divide-se, ainda, segundo o grau de desenvolvimento do doador, em cooperação entre países em desenvolvimento (a qual ocorre entre países com nível similar de desenvolvimento) e cooperação entre países com graus diferenciados de desenvolvimento, tópico este que será melhor analisado no item 3.4 do presente trabalho.
} 
a compreensão da saúde como tema a ser desenvolvido no âmbito da política internacional (Ibid.).

Desse modo, desde o início do século XIX vem sendo desenvolvidas ações para o controle das doenças na esfera internacional, até mesmo porque, com o crescente processo de industrialização e urbanização da Europa que ocorria à época, reconheceu-se que a decretação de quarentenas revela-se mais economicamente prejudicial do que o efetivo combate às endemias (Silvestre, 2007:43).

Nesse contexto, na metade do século XIX, tiveram início as denominadas “Conferências Sanitárias Internacionais”, tendo sido a primeira delas realizada em Constantinopla, em 1851, ocasião na qual se convencionou uma série de normas visando a promulgação de um Código Sanitário Internacional, para a instituição de quarentenas e notificações de casos de cólera e peste bubônica (Ibid.).

Tais Conferências constituíram fóruns de debate científico (e também político, naturalmente), pois estabeleciam normas e procedimentos comuns a serem adotados pelos países que enfrentavam surtos de cólera e peste bubônica, podendo tais iniciativas ser consideradas como sendo embrionárias do fenômeno cooperação internacional em saúde (Ibid.).

No âmbito do continente americano, destaca-se a criação, em 1902, do escritório da Oficina Pan-Americana da Saúde (OPAS), posteriormente denominada Organização Pan-Americana da Saúde (Silvestre, 2007:44).

A OPAS pode ser situada como sendo o mais antigo organismo direcionado, diretamente, para a cooperação internacional em saúde.

A partir de seu surgimento, foram gradualmente criadas diversas outras instituições, merecendo destaque a criação da Fundação Rockfeller, instituída em 1913, a qual se pautava pela atuação mediante a doação, sem fins lucrativos, para o desenvolvimento de atividades científicas, a serem realizadas em universidades e institutos de pesquisa (Ibid.).

Em 1946, já no âmbito da ONU, foi criada a Organização Mundial da Saúde (OMS), momento a partir do qual as duas organizações, OPAS e OMS, assumem o 
papel de cooperação na área da saúde perante a comunidade internacional (Silvestre, 2007:46).

Nesse contexto, a OPAS se estabeleceu como sendo a sede do escritório regional da OMS para atuação nas Américas, bem como organismo do sistema interamericano especializado em saúde (Ibid.).

Nas últimas décadas, além da forte atuação da OMS-OPAS, tem se verificado um crescente incremento da atuação dos Bancos Internacionais no campo da saúde internacional, bem como de organizações não-governamentais internacionais, entre as quais merecem destaque, pelo relevo de sua atuação, a Cruz Vermelha, bem como os Médicos Sem Fronteiras e os Médicos do Mundo.

Dessa forma, percebe-se que, através de diversas iniciativas, a ONU, as agências de cooperação (de países desenvolvidos, bem como de países emergentes), as organizações não-governamentais internacionais, bem como a filantropia internacional, tem colocado a questão do setor saúde como prioridade na agenda de cooperação internacional, bem como dos programas de ajuda para o desenvolvimento, em um processo que vem sendo denominado “diplomacia global da saúde”. (Buss; Leal, 2009).

A diplomacia global da saúde pode ser conceituada como sendo o conjunto de negociações desenvolvidas nos mais diversos níveis, que delineiam e gerenciam o ambiente das políticas globais em saúde, as quais, idealmente, produziriam os melhores resultados para a saúde de todos os países envolvidos, bem como implementa as relações entre os Estados, reforçando os compromissos dos atores internacionais em prol do objetivo comum de assegurar a saúde como direito humano e bem público (Buss; Leal, 2009:2540 apud Kickbusch I, et al., 2007).

\subsection{A mudança de paradigma na Cooperação Internacional em Saúde - Da cooperação norte-sul para a cooperação sul-sul:}

Embora, como visto, a cooperação internacional em saúde não seja um fenômeno recente, ela foi inicialmente exercida mediante um forte componente de 
verticalidade, ou seja, através de uma relação assimétrica entre os prestadores e os receptores da cooperação, no que comumente se denomina “cooperação norte-sul”.

Isto porque, em sua origem, a cooperação internacional em saúde ocorria através de vultuosas doações, oferecidas pelos países desenvolvidos aos países subdesenvolvidos, e se dava mediante a imposição de soluções transpostas de contextos sociais e políticos distintos, e não raras vezes inadequados às necessidades dos países receptores da cooperação, a qual, frequentemente, ocorria mediante a utilização de hard power, ainda que de maneira velada.

Esta verticalidade na cooperação, não raro, trazia consigo problemas relativos à sua pertinência e eficácia (Silvestre, 2007:50), uma vez que não levava em conta, de maneira alguma, o contexto fático do país receptor da ajuda, além de ser comumente destinada a solucionar problemas pontuais de saúde, não contribuindo para a verdadeira estruturação do sistema de saúde do país receptor deste modelo de cooperação ${ }^{8}$, providência esta, sim, que se revelaria muito mais eficaz.

A discussão em torno desta característica do modelo tradicional de cooperação internacional em saúde (a sua verticalização) revelou a circunstância de que este modelo não mais atendia às exigências do setor saúde, seja devido à recente reformulação do quadro dos atores internacionais, seja pela sua pouco efetividade.

A constatação da ineficácia deste modelo de cooperação internacional acarretou um debate global acerca da efetividade das ações até então realizadas no campo da saúde internacional, sobretudo no âmbito da cooperação norte-sul, tradicionalmente estruturada sob a forma de programas verticais, vinculados a doenças específicas e, por essas razões, notadamente ineficientes na estrtuturação sistemas de saúde dos países receptores.

\footnotetext{
${ }^{8}$ Como exemplo, podemos citar os inúmeros casos em que países desenvolvidos, frente às epidemias ou pandemias que afligem os países africanos, por exemplo, enviavam maciças doações de medicamentos de vacinas. Não obstante este ajuda se revelasse necessária naquele momento, ela em nada contribuía para a estruturação do sistema de saúde destes países, uma vez que somente resolvia um problema pontual e específico.
} 
A grande mudança oriunda deste debate residiu na mudança de paradigma de modelo adotado no âmbito da cooperação internacional em saúde, com a priorização de uma horizontalidade nesta cooperação.

Neste contexto, a cooperação norte-sul vem sendo gradualmente substituída por uma cooperação realizada entre países em desenvolvimento, os quais possuem uma relação mais simétrica entre si, em um fenômeno que vem sendo denominado “cooperação sul-sul” em saúde, ou cooperação horizontal. (Almeida et al., 2010:28)

Com efeito, em 1978, as delegações representativas de 178 Estados reuniramse em Buenos Aires, para uma Conferência sobre Cooperação Técnica entre Países em Desenvolvimento, aprovando posteriormente o Plano de Buenos Aires (PABA), que representa um marco histórico na doutrina da cooperação sul-sul.

E, posteriormente, entre 2008 e 2009, foi promovido um amplo debate acerca da cooperação sul-sul, o qual culminou na Conferência de Alto Nível das Nações Unidas sobre a Cooperação Sul-Sul, realizada em Nairóbi, em 2009, tendo como resultado a promulgação da Resolução 64/222 da Assembleia Geral da ONU, em cujo parágrafo 18 se apresenta uma definição do que seria a cooperação sul-sul.

Nesta ocasião, foi reafirmado que a cooperação sul-sul constitui uma iniciativa comum aos povos e aos países do sul, originária de afinidades e experiências compartilhadas, baseada em objetivos unos e solidariedade comum, e guiada, entre outros fatores, pelos princípios de respeito à soberania e às peculiaridades de cada nação, livres de quaisquer imposições.

Nesse contexto, o Brasil, como potência emergente global entre os países de renda média, tem se destacado no campo da diplomacia em saúde, no âmbito da cooperação sul-sul, com o que tem sido denominado "cooperação estruturante em saúde”, que reside no apoio ao desenvolvimento e estruturação dos sistemas de saúde, através da construção contínua de instituições estruturantes, assim como a formação de recursos humanos, como estratégia central para o incremento da potencialidade dos sistemas de saúde dos países em desenvolvimento (Buss; Leal, 2009:2540). 
Além disso, o Brasil vem apostando na constituição de blocos regionais, como estratégia de política internacional, nos quais a questão da saúde vem merecendo tratamento prioritário, como são os casos da União das Nações SulAmericanas (UNASUL), assim como a Comunidade dos Países de Língua Portuguesa (CPLP), os quais criaram Conselhos específicos para cuidar da questão da saúde, quais sejam a UNASUL Saúde e a CPLP Saúde.

O presente trabalho, após a contextualização dos diversos sistemas de saúde, assim como da cooperação internacional em saúde, dirige-se à análise específica da maneira como a questão da saúde vem sendo tratada no âmbito destes dois supracitados blocos, realizando, ao final, uma análise comparativa entre as estratégias por ambos adotadas, no que diz respeito ao incremento da questão relativa à atenção primária à saúde. 


\section{4 - A SAÚDE NO ÂMBITO DA COMUNIDADE DOS PAÍSES DE LÍNGUA PORTUGUESA (CPLP):}

\subsection{A Comunidade dos Países de Língua Portuguesa (CPLP):}

A Comunidade dos Países nos quais a língua portuguesa é oficialmente adotada foi criada no ano de 1996, na capital de Portugal (Lisboa), pelos chefes de Estado de Portugal, Brasil, Angola, Cabo Verde, Guiné-Bissau, Moçambique e São Tomé e Príncipe, sendo que, em 2002, após a sua independência, o Timor Leste se tornou o oitavo membro deste bloco regional ${ }^{9}$.

A CPLP possui, ainda, como países observados associados, a Guiné Equatorial, as Ilhas Mauricius e Senegal.

A CPLP tem como objetivos precípuos a agregação político-diplomática entre os seus membros, visando reforçar suas presenças individuais, assim como a da comunidade como um todo, no cenário internacional; a cooperação internacional em todos os domínios, aqui incluído o campo da saúde; assim como a contínua promoção e difusão da língua portuguesa.

A CPLP é composta pelos seguintes órgãos de direção e consultivo: a Conferência de Chefes de Estado e Governo, o Conselho de Ministros das Relações Exteriores, o Comitê de Concertação Permanente, o Secretariado Executivo, as Reuniões Ministeriais Setoriais (entre as quais se inclui a Reunião de Ministros da Saúde), a Reunião dos Pontos Focais de Cooperação, bem como o Instituto Internacional de Língua Portuguesa (IIPL).

As Conferências de Chefes de Estado e de Governo, órgão máximo de deliberação no âmbito da CPLP, devem ocorrer a cada 2 (dois) anos.

\footnotetext{
9 As informações ora apresentadas, relativas à CPLP, foram todas retiradas de seu endereço eletrônico, disponível em <http://www.cplp.org>. Acesso em 04/03/2011.
} 
Por sua vez, o Secretariado Executivo constitui o principal órgão deliberativo da CPLP, cuja sede fica em Lisboa, sendo dirigido por um Secretário com mandato de 2 (dois) anos, prorrogável por mais 2 (dois).

No que tange ao objeto do presente trabalho, cumpre ressaltar que a primeira reunião setorial de Ministros de Estado da Saúde da CPLP ocorreu em 2008, em Praia, Cabo Verde, ocasião na qual se decidiu pelo estabelecimento do Plano de Cooperação Estratégica em Sáude (PECS/CPLP), para vigorar pelo período de 2009 a 2012.

\subsection{A Cooperação em Saúde no âmbito da CPLP - O Plano Estratégico de Cooperação em Saúde (PECS/CPLP):}

Inicialmente, cumpre ressaltar que, entre os países membros da CPLP, verifica-se uma enorme assimetria no que tange às questões ligadas ao setor saúde, havendo uma significativa discrepância em relação aos índices de mortalidade e expectativa de vida de seus membros, assim como condições nutricionais, o que, de per si, tornou a elaboração de um Plano Estratégico de Cooperação uma tarefa árdua, na medida em que interesses e necessidades dos mais elevados níveis, por um lado, deveriam ser compatibilizados com possibilidades escassas de doação de recursos e recursos humanos (notadamente entre os países africanos), de outro lado.

Os sistemas de saúde dos países membros da CPLP ainda se revelam extremamente frágeis, notadamente no que tange à atenção primária à saúde, com cobertura deficiente, insuficiência no número de unidades de saúde, dificuldades de gestão, pessoal incapacitado e em número insuficiente, assim como configuração tecnológica defasada. Tais circunstâncias revelam um gasto mínimo em saúde, insuficiente, inclusive, para a devida cobertura da atenção primária à saúde, contexto no qual o apoio técnico e financeiro internacional mostra-se vital para o pleno desenvolvimento destes sistemas de saúde (Buss; Ferreira, 2010b:109). 
Entre os países membros da CPLP, a opção pela cooperação sul-sul foi uma alternativa natural, facilitada sobremaneira pela questão idiomática (o que facilita o intercâmbio de recursos humanos qualificados para o setor saúde), assim como por identidades políticas e culturais (Ibid.).

Assim, foi elaborado o Plano Estratégico de Cooperação em Saúde (PECS/CPLP), o qual considerou a profunda assimetria da situação sócio-sanitária dos países membros da CPLP, assim como suas capacidades de respostas aos principais problemas sanitários que enfrentam diuturnamente, trazendo, como resultado final, um processo de cooperação comprometido com os princípios de apropriação, alinhamento e harmonização (Ibid.). ${ }^{10}$

O PECS/CPLP foi aprovado pela Declaração do Estoril ${ }^{11}$ (CPLP, 2009b), em maio de 2009, destinando-se a vigorar pelo período de 2009 a 2012, consagrando-se como um grande pacto celebrado pelos Ministros de Estado dos 8 (oito) países membros.

O PECS tem como principal finalidade "contribuir para o reforço dos sistemas de saúde dos Estados membros da CPLP, de forma a garantir o acesso universal a cuidados de saúde de qualidade”. Aqui já se percebe uma grande similaridade entre os sistemas de saúde dos países membros da CPLP, uma vez que eles adotaram o sistema de saúde público de acesso universal, circunstância esta que, de per si, já facilita a cooperação.

Os objetivos do PECS/CPLP são: (i) o estabelecimento de ações de cooperação multilateral em saúde, com base nos eixos estratégicos e projetos prioritários previamente indentificados; e (ii) a definição das estruturas de operacionalização do PECS/CPLP, assim como a definição dos procedimentos para a estruturação, apresentação, financiamento e implementação dos projetos.

\footnotetext{
${ }^{10}$ O Plano Estratégico de Cooperação em Saúde da CPLP (PECS/CPLP) pode ser acessado no endereço eletrônico da CPLP (<www.cplp.org>). Serão a seguir apresentadas as suas principais linhas, assim como seus objetivos, premissa fundamental para a conclusão da análise ora proposta.

11 A Declaração do Estoril pode ser acessada no seguinte endereço eletrônico da CPLP <http://www.cplp.org/Admin/Public/DWSDownload.aspx?File=\%2fFiles\%2fFiler\%2fcplp\%2fredes\%2f saude\%2fIIReuniaoEstoril\%2fDeclarEstorilFINAL_15Maio.pdf>. Acesso em 05/03/2011.
} 
O PECS/CPLP tem como pano de fundo os Objetivos para o Desenvolvimento do Milênio (ODM) ${ }^{12}$, revelando como missão precípua “apoiar os Estados membros na consecução de metas relativas à melhoria das condições de saúde das suas populações, visando prestar uma contribuição para a redução da mortalidade infantil, melhoria da saúde materno-infantil e combate ao VIH/SIDA, malária e outras doenças graves.”13

O PECS/CPLP identificou sete eixos estratégicos para a definição dos projetos prioritários, assim como das metas a serem atingidas, da maneira listada abaixo:

1) Formação e Desenvolvimento da Força de Trabalho em Sáude;

2) Informação e Comunicação em Saúde;

3) Investigação em Saúde;

4) Desenvolvimento do Complexo Produtivo em Saúde;

5) Vigilãncia Epidemiológica e Monitorização da Situação em Saúde;

6) Emergências e Desastres Naturais; e

7) Promoção e Proteção da Saúde.

O primeiro eixo definido pelo PECS/CPLP, a Formação e Desenvolvimento da Força de Trabalho em Saúde, embora diga respeito a um ponto crítico em qualquer sistema de saúde, adquire contornos dramáticos nos países africanos membros da CPLP, tanto pela insuficiência de pessoal qualificado (causada em

${ }^{12}$ Os Objetivos para o Desenvolvimento do Milênio constituem 8 (oito) metas estabelecidas pela ONU, as quais se pretendem ser alcançadas por todos os países membros da ONU até 2015 , sendo que algumas destas metas possuem relação direta com o setor saúde. Elas seguem abaixo transcritas:

1) Erradicar a pobreza extrema e a fome;

2) Atingir o ensino básico universal;

3) Promover a igualdade entre os sexos e a autonomia das mulheres;

4) Reduzir a mortalidade infantil;

5) Melhorar a saúde materna;

6) Combater o HIV/AIDS, a malária e outras doenças;

7) Garantir a sustentabilidade ambiental; e

8) Estabelecer uma parceria mundial para o desenvolvimento.

${ }^{13}$ No âmbito do continente africano, é comum a incidência do que se denominou como sendo as "três grandes" doenças - HIV/AIDS, malária e tuberculose. 
grande parte pela centros de formação e educação) quanto pelo brain draining ${ }^{14}$, que acaba retirando destes países os pouco profissionais qualificados (Buss; Ferreira, 2010b:110).

Dessa forma, neste eixo específico visa-se alcançar, através da cooperação internacional, os seguintes objetivos: (i) possibilitar o amplo acesso dos países membros a informações e análise sobre recursos humanos na CPLP; (ii) assegurar a qualidade da formação médica e de outras profissões de saúde no âmbito da CPLP; bem como (iii) fortalecer a capacidade de formação técnica para o sistema de saúde, assim como a capacidade de formação em nível de pós-graduação em saúde.

O segundo eixo estratégico elencado pela CPLP como prioritário diz respeito à Informação e Comunicação em Saúde, através de qual se pretende incrementar a partilha de informações em saúde, assim como o fortalecimento de práticas técnicocientíficas coletivas, bem como a ampliação da difusão e do acesso de informações técnico-científicas na área de saúde, a serem implementadas através da criação do Portal CPLP/Saúde, da Rede de Bibliotecas Virtuais em Saúde da CPLP, bem como uma Revista Científica em Saúde no âmbito da CPLP.

O terceiro eixo estratégico do PECS/CPLP diz respeito à Investigação em Saúde, através do qual se pretende ampliar as atividades de cooperação em ciência, tecnologia e inovação em saúde, por meio do fortalecimento da investigação científica e saúde pública, com prioridade para as áreas de vigilância em saúde, gestão dos sistemas de saúde e pesquisa biomédica.

Por sua vez, o quarto eixo elencado pelo PECS/CPLP como estratégico diz respeito ao Desenvolvimento do Complexo Produtivo da Saúde, o qual possui como objetivo: (i) desenvolver a indústria farmacêutica, o que reduziria a dependência externa dos países da CPLP, assim como ampliaria o acesso da população dos países membros à assistência farmacêutica; e (ii) apoiar e qualificar a organização dos serviços de manutenção dos equipamentos em saúde, o que contribuiria sobremaneira

\footnotetext{
${ }^{14} \mathrm{O}$ brain draining diz respeito ao fenômeno que ainda assola diversos países subdesenvolvidos (e também vários em desenvolvimento), segundo o qual os poucos profissionais tecnicamente qualificados para o trabalho em determinada área migram para países desenvolvidos, por força de melhores ofertas de trabalho e remuneração.
} 
no sentido de evitar a perda de equipamentos médicos de alto valor, que frequentemente ocorre por falta de manutenção.

Aqui, merece destaque o apoio que o Estado brasileiro vem dando à Moçambique, através de um projeto de cooperação para a implantação de uma fábrica estatal destinada à produção de medicamentos básicos e antiretrovirais, que vem sendo desenvolvido pela Fundação Oswaldo Cruz (FIOCRUZ) e o Ministério da Saúde de Moçambique (Buss; Ferreira, 2010b:111).

O quinto eixo estratégico elencado pelo PECS/CPLP diz respeito à Vigilância Epidemiológica e Monitorização da Situação em Saúde, o qual tem por objetivo: (i) garantir o adequado acompanhamento dos resultados alcançados pelos membros da CPLP em relação aos Objetivos do Milênio (ODM), bem como (ii) a criação de estruturas laboratoriais aptas a garantir o diagnóstico oportuno e confiável das doenças de maior prevalência entre os membros da CPLP, tais como o HIV/AIDS, a malária e a tuberculose (notadamente nos países africanos membros da CPLP).

Já o sexto eixo estratégico do PECS/CPLP refere-se às Emergências e Desastres Naturais em Saúde, possuindo como objetivo precípuo ampliar a coordenação das ações (bem como a velocidade das respostas) a situações de emergência nos Estados Membros da CPLP, eixo este que se revela extremamente necessário, uma vez que países com níveis elevados de carência em matéria de saúde frequentemente possuem enormes dificuldades para lidar com situações inesperadas, (como um surto ou endemia de uma doença ainda não muito conhecida), ou mesmo desastres naturais com consequências severas no âmbito sanitário.

E, por último, o sétimo eixo estratégico do PECS/CPLP refere-se à Promoção e Proteção em Saúde, visando promover o intercâmbio, entre os países membros da CPLP, de experiências inovadoras no campo da promoção da saúde, a ser implementado através dos seguintes projetos estruturantes: (i) a criação das Comunidades Saudáveis, projetos pilotos voltados ao desenvolvimento local de ações voltadas à melhoria das condições de vida das populações interessadas; (ii) implantação de um programa de sensibilização dos curandeiros, bruxos e demais médicos e parteiras tradicionais (presentes em enorme número sobretudo no 
continente africano) para o reconhecimento e a derivação ao sistema de saúde de patologias específicas, bem como (iii) o desenvolvimento de estudos para a implementação de ações intersetoriais destinadas ao enfrentamento dos determinantes sociais da saúde.

Após a definição dos sete eixos estratégicos para a cooperação, o PECS/CPLP dispõe que o financiamento de suas ações será garantido por diversas fontes, incluindo recursos disponibilizados pelos países membros da CPLP, bem como por organizações internacionais e outros parceiros, ressaltando, ainda, que a mobilização de recursos junto a outros doadores bilaterais e multilaterais afigura-se, igualmente, como uma estratégia importante para a captação dos recursos destinados à execução do PECS/CPLP.

Por fim, restou definido que o PECS/CPLP 2009-2012 apresenta um Orçamento Indicativo de cerca de quatorze milhões de euros, ficando 67\% (sessenta e sete por cento) deste valor destinado a ações relativas ao eixo estratégico 1 (Formação e Desenvolvimento da Força de Trabalho em Sáude).

A implementação dos projetos, em cada um dos países membros da CPLP, ficará sob a responsabilidade dos respectivos Ministérios da Saúde.

Uma vez aprovado o texto do PECS/CPLP, o último passo para a sua implantação consistiu na Reunião de Parceiros para o Desenvolvimento do PECS/CPLP, ocorrida em Lisboa, no ano de 2009, na qual Brasil e Portugal ofereceram, ambos, doações iniciais no valor de USD 250 mil, as quais passaram a compor o Fundo de Saúde da CPLP, especialmente criado para financiar as ações do PECS/CPLP (Buss; Ferreira, 2010b:112).

O PECS/CPLP tem tido uma excelente recepção por parte dos países membros da CPLP, circunstância esta que tem levado a própria CPLP a aplicar modelos similares de cooperação a outras áreas sociais igualmente deficitárias, tais como o meio ambiente e a educação, entre outros (Ibid.). 


\subsection{Análise Crítica do PECS/CPLP:}

Inicialmente, deve-se ressaltar a dificuldade relativa à elaboração de um plano conjunto para cooperação em saúde que tenha como partes países com uma assimetria tão grande no que tange aos sistemas de saúde envolvidos (tanto em relação à estruturação quanto em relação à eficácia dos serviços prestados), contexto no qual a iniciativa de elaboração do PECS/CPLP é digna de aplausos.

No entanto, embora tenha sete eixos estruturantes, e diversos projetos para implantação previamente estabelecidos, constata-se facilmente que o seu orçamento indicativo (de cerca de quatorze milhões de euros) é nitidamente insuficiente para a sua devida implementação, contexto no qual a captação externa de recursos revela-se indispensável, sob pena de ineficácia da execução do PECS/CPLP.

Ademais, a vinculação de 67\% (sessenta e sete) por cento do montante de seus recursos orçamentários para a implementação das ações de um único eixo estruturante (Formação e Desenvolvimento de Recursos Humanos na Área da Saúde), embora tenha como nítido objetivo reduzir a falta de profissionais capacitados para atuar na área (fenômeno verificado sobretudo nos países africanos), pode vir a comprometer seriamente a implementação dos projetos relativos aos seis outros eixos do PECS/CPLP, caso não ocorra uma entrada significativa de recursos externos.

O dois últimos eixos do plano (Emergências e Desastres Naturais e Promoção e Proteção da Saúde), os quais são nitidamente voltados ao desenvolvimento dos sistemas de saúde dos países africanos membros da CPLP, revelam-se de extrema importância para estes países.

No que tange ao eixo Emergências e Desastres Naturais, é sabido que os membros do CPLP advindos do continente africano, embora sejam constantemente vitimados por pandemias de determinadas doenças, assim como por desastres naturais, revelam-se nitidamente despreparados (e desestruturados) para combater tais fenômenos, contexto no qual a cooperação advinda dos demais membros da CPLP revela-se essencial. Inclusive, os responsáveis pela articulação deste eixo são 
Brasil e Portugal, sendo que, neste ponto, a experiência da Fundação Oswaldo Cruz (FIOCRUZ), indubitavelmente, contribuirá em muito para o desenvolvimento dos sistemas de saúde dos países africanos membros da CPLP.

Em relação ao sétimo eixo do PECS/CPLP, qual seja a Promoção e Proteção da Saúde, é digno de louvor o fato deste plano ter levado em consideração características fortemente arraigadas na cultura sanitária africana, tais como a presença maciça das figuras dos “curandeiros, bruxos e outros médicos e parteiras naturais”, cuja existência em elevado número ocorre, precipuamente, pela falta de profissionais médicos qualificados para o atendimento à população africana. Aqui, revela-se essencial a oferta a estes profissionais de algum tipo de programa de qualificação para a atendimento à população, uma vez que não se desconhece a circunstância de que, embora prestem um serviço relevante, tais profissionais são nitidamente desqualificados do ponto de vista técnico, causando, não raro, um significativo número de óbitos no desempenho de suas funções. E, por último, este eixo também prevê a instauração das "Comunidades Saudáveis", mediante o desenvolvimento de ações voltadas para a melhoria da condição de vida das populações, igualmente essenciais para os países membros da CPLP.

No que tange especificamente ao desenvolvimento da atenção primária à saúde, critério que será utilizado como paradigma para a análise comparativa ora proposta, o PECS/CPLP, embora revele grande preocupação com o seu incremento, não fica imune a críticas.

Efetivamente, no que tange à questão da atenção primária à saúde, verifica-se que os dois eixos do PECS/CPLP a ela diretamente conectados são o eixo 1 (Formação e Desenvolvimento de Recursos Humanos em Saúde) e o eixo 7 (Promoção e Proteção da Saúde), que possuem projetos diretamente ligados ao seu incremento, uma vez que visam o fortalecimento da formação técnica em saúde, e ainda a implantação das Comunidades Saudáveis, de um Programa de sensibilização 
de curandeiros, bem como o desenvolvimento de estudos para o enfrentamento direto das determinantes sociais da saúde ${ }^{15}$.

No que tange especificamente ao eixo 7 do PECS/CPLP (Promoção e Proteção da Saúde), constata-se que a FIOCRUZ ficou responsável por toda sua articulação, de maneira que o Brasil, certamente, exercerá um papel de destaque neste eixo do PECS/CPLP, uma vez que nossa atenção primária, embora ainda deficiente, revela-se melhor estruturada do que a dos países africanos membros da CPLP.

No entanto, uma vez que o eixo 7 somente prevê três projetos estruturantes (as já citadas Comunidades Saudáveis, o Programa de sensibilização de curandeiros, bruxos e outros médicos e parteiras tradicionais, bem como o desenvolvimento de estudos para o enfrentamento das determinantes sociais da saúde), a eficácia do PECS/CPLP no incremento da atenção primária à saúde de seus países membros dependerá dos projetos de cooperação que venham a ser firmados após a sua vigência, os quais serão objeto de estudo no próximo tópico.

\subsection{Análise da eficácia do PECS/CPLP no que tange ao incremento da atenção primária à saúde nos sistemas de saúde de seus países membros:}

No presente tópico, será apresentada uma breve análise da eficácia do PECS/CPLP no que diz respeito ao fortalecimento da atenção primária à saúde dos países membros da CPLP.

A metodologia aqui utilizada, em apertada síntese, residiu na análise da situação atual de implementação do PECS/CPLP, bem como nos projetos de cooperação que foram firmados após o início de sua vigência entre os países

\footnotetext{
${ }^{15}$ Os determinantes sociais da saúde, em apertada síntese, podem ser compreendidas como sendo o conjunto de fatores econômicos e sociais que possuem influência sobre a saúde, tais como renda, educação, emprego, desenvolvimento infantil, cultura, gênero e condições sanitárias e ambientais.
} 
membros, cujo objeto resida, especificamente, no incremento da atenção primária à saúde.

Conforme já exposto, o eixo 7 do PECS/CPLP (Promoção e Proteção da Saúde) tem a FIOCRUZ como a responsável pela sua articulação, o que, de per si, acarreta em uma maior participação brasileira nos projetos de cooperação dele decorrentes.

Atualmente, encontram-se em andamento sete projetos de cooperação firmados entre o Brasil e os Países membros da CPLP, diretamente focados no incremento da atenção primária à saúde, os quais seguem apontados abaixo:

a) Um projeto firmado entre o Ministério da Saúde brasileiro e Moçambique, cujo objeto reside no fortalecimento das ações de alimentação e nutrição;

b) Um projeto firmado entre o Ministério da Saúde e o Ministério das Relações Exteriores brasileiros e Moçambique, com vistas ao fortalecimento da odontologia neste País;

c) Um projeto firmado entre o Ministério da Saúde brasileiro e Moçambique, para o fortalecimento da terapia comunitária;

d) Um projeto a ser firmado entre o Ministério da Saúde e a FIOCRUZ, com Angola, cujo objeto consiste na revitalização da atenção primária à saúde;

e) Um projeto a ser firmado entre a Universidade do Rio Grande do Sul e a Agência Brasileira de Cooperação com Angola, para colaboração binacional para o desenvolvimento da atenção primária à saúde;

f) Um projeto firmado entre o Ministério da Saúde brasileiro e a Secretaria Estadual de Saúde do Estado da Bahia com os países da CPLP, cujo objeto consiste na qualificação do cuidado na atenção primária à saúde, bem como na mobilização comunitária em diabetes; e

g) Um projeto firmado entre o Ministério da Saúde brasileiro e Portugal, cujo objeto consiste em visitas recíprocas para participação em conferências e mostras relativas a Programas de Saúde em Família. 
Ademais, em relação à implementação do projeto Comunidades Saudáveis, igualmente previsto no eixo 7 do PECS/CPLP, encontram-se previstas, para o primeiro semestre do presente ano, a realização de oficinas junto aos países membros da CPLP, para planejamento do projeto junto às comunidades e definição de prioridades, para posterior execução.

No que tange ao eixo 1 do PECS/CPLP (Formação e Desenvolvimento da Força de Trabalho em Saúde), o qual igualmente se encontra ligado ao incremento da atenção primária à saúde dos países membros, o Plano de Trabalho das Escolas Técnicas de Saúde da CPLP já foi elaborado, e no momento estão sendo captados recursos externos para a sua execução.

Ante todo o exposto, conclui-se que, apesar do PECS/CPLP possuir somente dois eixos especificamente conectado com a questão do incremento da atenção primária à saúde de seus países membros (os eixos 1 e 7), após o início de sua vigência diversos projetos de cooperação relativos à APS já foram firmados, o que nos permite concluir no sentido de que o conteúdo do PECS/CPLP, embora não imune a críticas, vem efetivamente colaborando para o fortalecimento da atenção primária à saúde de seus países membros, notadamente nos países africanos membros da CPLP. 


\section{5 - A SAÚDE NO ÂMBITO DA UNIÃO DAS NAÇÕES SUL-AMERICANAS (UNASUL)}

\subsection{A União das Nações Sul-Americanas (UNASUL):}

A União das Nações Sul-Americanas constitui uma comunidade formada por doze países da América do Sul (Argentina, Bolívia, Brasil, Chile, Colômbia, Equador, Guiana, Paraguai, Peru, Suriname, Uruguai e Venezuela), tendo sido criada formalmente em Brasília, em maio de $2008{ }^{16}$

A UNASUL congrega dois blocos regionais anteriormente constituídos (o MERCOSUL e a COMUNIDADE ANDINA), sendo considerado por alguns analistas como sendo o primeiro genuíno bloco político regional apto a representar um contraponto ao poder político dos Estados Unidos em nosso hemisfério (Buss; Ferreira, 2010b:112).

A UNASUL tem como objetivo precípuo “construir, de forma participativa e consensual, um espaço de integração e união nos campos da cultural, social, econômico e político entre seus povos, outorgando prioridade ao diálogo político, às políticas sociais, saúde, educação, energia, infra-estrutura, financiamento e meio ambiente, entre outros, com vistas a eliminar as desigualdades sócio-econômicas, lograr a inclusão social e a participação cidadã, fortalecer a democracia e reduzir as assimetrias, no marco do fortalecimento da soberania e independência dos Estadosmembros.”

Nos termos de seu Tratado Constitutivo, a estrutura institucional da UNASUL é composta pelos seguintes órgãos: o Conselho de Chefes de Estado e de Governo, o Conselho dos Ministros de Relações Exteriores, o Conselho de Delegados e a Secretaria Geral.

\footnotetext{
16 A UNASUL possui endereço eletrônico específico (do qual foram extraídas as informações apresentadas neste Capítulo) - <http://www.pptunasur.com>. Acesso em 05/03/2011.
} 
Atualmente, a UNASUL conta com oito Conselhos Ministeriais, para deliberações relativas às seguintes matérias: saúde, energia, defesa, infra-estrutura e planejamento, desenvolvimento social, problema mundial das drogas, educação, cultura, ciência, tecnologia e informação e economia e finanças.

A UNASUL vem se revelando como um instrumento útil no que tange à solução pacífica de controvérsias regionais, bem como para o fortalecimento dos regimes democráticos no âmbito do continente sul-americano.

\subsection{A Cooperação em Saúde no âmbito da UNASUL - O Plano Quinquenal 2010/2015:}

Ainda na primeira reunião de Chefes de Estado e de Governo da UNASUL, ocorrida em 2008, no Brasil, foi constituído o Conselho Sul-Americano de Saúde, o que demonstra, desde o início, a preocupação da UNASUL com o tema saúde.

O Conselho de Saúde da UNASUL é composto pelos Ministros de Saúde dos doze Estados Membros, tendo como objetivo consolidar a integração da América do Sul no campo saúde, através de políticas baseadas em acordos mútuos, atividades coordenadas e esforços de cooperação ente os países envolvidos.

A Agenda Sul-Americana de Saúde, aprovada pelo Conselho de Saúde da UNASUL, contempla os temas abaixo previstos:

1) Elaboração da Política Sul-Americana de Vigilância e Controle de Eventos em Saúde;

2) Desenvolver Sistemas Universais de Saúde;

3) Promover o acesso universal a medicamentos e outros insumos para a saúde e desenvolver o complexo produtivo da saúde na América do Sul;

4) Promover a saúde e enfrentar de forma conjunta seus determinantes sociais; e

5) Desenvolver recursos humanos em saúde. 
Logo após o estabelecimento da Agenda Sul-Americana, o Conselho de Ministros da Saúde decidiu, ainda, pela elaboração de um Plano Quinquenal da Saúde da UNASUL, o qual foi aprovado, em 30 de abril de 2010, para vigorar no período de 2010 a 2015, e cujos principais pontos seguirão abaixo transcritos. ${ }^{17}$

O Plano Quinquenal, inicialmente, afirma os fundamentos nos quais se apóia, consignando que: (i) a saúde é um direito fundamental do ser humano e da sociedade, constituindo um componente vital para o desenvolvimento humano; (ii) a saúde é um importante fator para a integração das nações membros da UNASUL; (iii) a saúde deve integrar-se em um conceito maior de proteção social, desempenhando um importante papel no desenvolvimento social harmônico; (iv) a UNASUL Saúde poderá levar em conta os apontamentos aprovados pelos Estados membros da OPAS, e tem como objetivo promover a redução das assimetrias existentes entre os sistemas de saúde de seus membros; (v) a região sul-americana conta com capacidades e experiências em saúde que deverão ser levadas em conta em prol da integração dos Estados membros da UNASUL; e (vi) a UNASUL Saúde buscará promover a responsabilidade e a participação cidadã nos temas de saúde, tendo sempre presentes os princípios da solidariedade, complementariedade, respeito à diversidade e multiculturalismo.

No que tange aos sistemas de saúde dos países membros da UNASUL, o Plano Quinquenal destaca a circunstância de que estes alcançaram um grau assimétrico de desenvolvimento e cobertura, sendo que suas organizações e estruturas se diferem quanto ao modo de financiamento, marco legal e normativo, papel do Estado, coordenação, setores participantes, tendo alguns deles, inclusive, sofrido grandes mudanças em seus marcos legais (causadas pelas reformas de Estado que afetaram o setor saúde, sobretudo na década de 1990).

Assim, os benefícios (assim como os problemas) atribuídos às reformas nos sistemas de saúde dos membros da UNASUL causaram o surgimento de enormes desafios a serem enfrentados, entre os quais se destacam: fortalecer o papel da autoridade sanitária central, fortalecer e monitorar as funções essenciais de saúde

17 O Plano Quinquenal da Saúde encontra-se disponível no endereço eletrônico <http://www.pptunasur.org>. Acesso em 05/03/2011. 
pública, buscar mecanismos de integração da rede pública, recuperar o nível de financiamento para assegurar desempenhos satisfatórios dos sistemas de saúde, assim como fortalecer a prestação de serviços de atenção primária à saúde.

No que tange aos recursos humanos em saúde, o Plano Quinquenal destaca a circunstância de que, entre 1995 e 2005, se manteve um crescimento positivo do quantitativo de recursos humanos em saúde, embora este crescimento tenda a diminuir. Ressaltou, ainda, que há uma enorme má-distribuição destes profissionais de saúde no território sul-americano, que se encontram concentrados nas grande cidades, uma vez que as áreas urbanas apresentam de oito a dez vezes mais médicos do que as áreas rurais. E, por último, destacou o fato de que um número importante dos países da UNASUL não contam com o quantitativo de profissionais de saúde suficientes para uma cobertura mínima. ${ }^{18}$

Uma vez contextualizada, ainda que de maneira sucinta, a situação e os problemas atuais a serem enfrentados pelos sistemas de saúde dos países membros da UNASUL, o Plano Quinquenal delineia cinco áreas de trabalho, apresentando ainda, para cada uma destas áreas, os seus objetivos, resultados a serem alcançados e as atividades planejadas visando estes resultados.

Assim, as áreas de trabalho do Plano Quinquenal são as que seguem abaixo descritas:

1) Rede Sul-Americana de Vigilância e Resposta em Saúde;

2) Desenvolvimento de Sistemas de Saúde Universais;

3) Acesso Universal a Medicamentos;

4) Promoção da Saúde e Ação sobre os Determinantes Sociais da Saúde; e

5) Desenvolvimento e Gestão de Recursos Humanos em Saúde.

Em relação à primeira área de trabalho, qual seja a Rede Sul-Americana de Vigilância e Resposta em Saúde, o Plano Quinquenal tem como objetivo estratégico

\footnotetext{
${ }^{18}$ Uma cobertura adequadamente prestada por um sistema de saúde, segundo levantamentos estatísticos realizados, deve contar com um número de 25 (vinte e cinco) profissionais de saúde para cada 25.000 (vinte e cinco mil) habitantes.
} 
estabelecer uma rede de vigilância epidemiológica e controle de enfermidades transmissíveis, crônicas não transmissíveis e eventos em saúde pública.

No âmbito desta rede, o Plano Quinquenal objetiva, entre outras ações, criar e operacionalizar um sistema de informações para notificação de enfermidades (o VIGISAS/RAVE), assim como uma Rede de Dengue-UNASUL (para mitigar o impacto da dengue na região sul-americana), e, ainda, impulsionar um Programa SulAmericano de Imunização (uma vez que a imunização, ainda nos dias atuais, é deficiente em vários dos sistemas de saúde dos países da UNASUL).

Em relação à segunda área de trabalho, o Desenvolvimento de Sistemas Universais de Saúde, o Plano Quinquenal revela como objetivo estratégico a formação e o desenvolvimento de sistemas de saúde universais em todos os países da América do Sul, para que, então, se melhore a equidade e o acesso a estes sistemas, bem como se implemente um mecanismo para o controle da evolução destes sistemas de saúde.

Neste ponto, o Plano Quinquenal estabelece como atividades a serem implementadas, entre outras: (i) a revisão da legislação dos países membros, para que se verifique se o direito à saúde é efetivo nos ordenamentos nacionais; (ii) a formação de redes integradas de saúde, baseadas na atenção primária à saúde; assim como (iii) o fortalecimento da reciprocidade e da complementariedade no que tange aos sistemas de saúde dos Estados membros da UNASUL, especialmente nas áreas fronteiriças.

No que tange à terceira área de trabalho do Plano Quinquenal, o Acesso Universal a Medicamentos, constata-se que o objetivo estratégico que se pretende alcançar consiste no desenvolvimento de estratégias e planos de trabalho (a fim se melhorar o acesso da população sul-americana a medicamentos), através de recomendações para o fortalecimento das capacidade produtiva de medicamentos da região, bem como a redução das barreiras ao acesso aos medicamentos, advindas da existência de direitos de propriedade intelectual.

Para que se alcancem estes resultados, o Plano Quinquenal define a realização das seguintes medidas: (i) a definição precisa da real necessidade de medicamentos 
dos países membros da UNASUL, segundo o perfil de mortalidade destes países; (ii) o mapeamento da real capacidade de produção (pública e privada) de medicamentos dos Estados membros da UNASUL; (iii) a implementação de um banco de preços de medicamentos no âmbito da UNASUL; (iv) a promoção de novas negociações de preços e compras de medicamentos, bem como (v) a formulação de recomendações no sentido de se ampliar a utilização de medicamentos genéricos.

Na quarta área de trabalho do Plano Quinquenal, a Promoção da Saúde e a Ação sobre os Determinantes Sociais da Saúde, é apresentado como objetivo estratégico o fortalecimento da promoção da saúde e da ação sobre os seus determinantes sociais, visando reduzir as dificuldades enfrentadas pelos países da UNASUL neste campo, mediante a produção de informação, a articulação intersetorial e a participação comunitária na formulação, execução e acompanhamento das políticas públicas de saúde.

Neste ponto, são previstas as seguintes atividades: (i) a criação de mecanismos de comunicação social que garantam a o acesso a informações relativas à promoção da saúde, bem como sobre os seus determinantes sociais, aos mais diversos segmentos da população sul-americana, bem como (ii) fomentar a articulação com as diversas instâncias da UNASUL, no sentido de que as políticas, programas e ações a serem propostas levem sempre, em consideração, o impacto que venham a causar na saúde e em seus determinantes sociais.

E, por último, a quinta área de trabalho do Plano Quinquenal, o Desenvolvimento e Gestão de Recursos Humanos em Saúde, elenca como objetivo estratégico fortalecer a condução, a formulação, a implementação e a gestão dos recursos humanos em saúde, de uma maneira geral, bem como nas áreas técnica de saúde da Agenda de Saúde da UNASUL.

Para que resultados venham a ser alcançados nesta área de trabalho, o Plano Quinquenal destaca a necessidade de realização das seguintes atividades, entre outras: (i) reforçar, em cada um dos países, a governança dos Ministérios de Saúde respectivos, no que tange à gestão do trabalho, formação e capacitação dos recursos humanos em saúde; e também (ii) a criação do Instituto Sul-Americano de Governo 
de Saúde (ISAGS), através do qual se implementarão seminários, cursos e outras medidas aptas à capacitação dos recursos humanos em saúde.

No que tange ao financiamento do Plano Quinquenal de Saúde da UNASUL, restou consignado que as suas fontes de financiamentos são constituídas pelos fundos voluntários nacionais (para ao quais os países membros verterão anualmente recursos destinados ao financiamento das ações previstas), assim como pela mobilização de recursos externos.

A responsabilidade política pelo cumprimento dos objetivos do Plano Quinquenal ficou a cargo do Conselho de Saúde Sul-Americano, que velará para que a sua execução reste alinhada com os compromissos já firmados no sentido de se criar um espaço para a integração da saúde entre os países membros da UNASUL.

E, por fim, ficou determinado que a responsabilidade pela implementação do Plano Quinquenal será dos Comitês Coordenadores, que receberão o devido apoio dos Grupos Técnicos porventura instituídos.

A avaliação dos resultados estratégicos já alcançados no curso da execução do Plano Quinquenal será efetuada na metade de seu curso (ou seja, em maio de 2013), sendo que os resultados alcançados por esta avaliação serão utilizados para a reformulação do Plano, para que com isso se garanta o total cumprimento dos Objetivos Estratégicos do Plano Quinquenal.

\subsection{Avaliação Crítica do Plano Quinquenal de Saúde da UNASUL:}

O Plano Quinquenal de Saúde da UNASUL (2010-2015) constitui um documento essencialmente programático, no sentido de que prevê uma série de resultados a serem alcançados, sem, contudo, dispor o efetivo caminho que deverá ser trilhado para que efetivamente se alcance tais metas.

Ou seja, ele acaba por se revelar como sendo mais uma carta de intenções (no sentido do estabelecimento de objetivos comuns) do que um Plano propriamente dito, notadamente em função deste caráter pragmático. 
No que tange ao seu financiamento, percebe-se que o Plano não possui um orçamento previamente fixado, ficando a mercê, por esta razão, dos recursos que vierem a ser depositados pelos países membros (em relação aos quais, é importante frisar, não existe nenhum critério fixado para o seu cálculo, o que deveria ter sido objeto de debate prévio, frente à assimetria das condições econômicas dos países membros da UNASUL), bem como da capacitação de recursos externos.

No que tange à atenção primária à saúde, as três áreas de trabalho a ela diretamente vinculadas são o Desenvolvimento e Gestão de Recursos Humanos em Saúde, o Desenvolvimento de Sistemas de Saúde Universais e a Promoção da Saúde e Ação sobre os determinantes sociais da saúde.

No entanto, as metas fixadas para o desenvolvimento da atenção primária à saúde são todas de cunho genérico (contexto no qual se reconheceu a importância do aprimoramento da atenção primária à saúde dos sistemas de saúde dos países membros da UNASUL), uma vez que não restaram previstas quais seriam as medidas a serem adotadas, para que efetivamente se alcance tal resultado.

E isso se revela extremamente necessário no âmbito dos sistemas de saúde dos países sul-americanos, uma vez que diversos dos Estados membros da UNASUL possuem um enorme contingente de populações rurais (tais como a Bolívia e o Peru), situadas geograficamente distantes dos grandes centros urbanos, nos quais ficam normalmente concentradas as ofertas de serviços de saúde.

Nesse contexto, o melhor desenvolvimento da atenção primária à saúde se revela essencial, uma vez que a presença de pequenos centros ou postos de saúde junto a estas comunidades rurais seria da mais extrema importância (pois prestariam um serviço de saúde essencial às populações rurais, as quais possuem, via de regra, uma grande dificuldade de acesso aos grandes centros urbanos).

Assim, percebe-se facilmente que, na realidade cotidiana de inúmeros países membros da UNASUL, o fortalecimento da atenção primária à saúde revela-se de crucial importância, ponto no qual o Plano Quinquenal de Saúde da UNASUL não fica de forma alguma imune a críticas. 
Espera-se que, no ano de 2013, por ocasião da revisão do conteúdo e dos resultados já alcançados na execução do Plano Quinquenal, a questão do fortalecimento da atenção primária à saúde seja revista, com a conseqüente adoção de medidas efetivas visando o seu pleno desenvolvimento.

\subsection{Análise da eficácia do Plano Quinquenal no que tange ao incremento da atenção primária à saúde nos sistemas de saúde de seus países membros:}

No presente tópico, será apresentada uma breve análise da eficácia do Plano Quinquenal no que diz respeito ao fortalecimento da atenção primária à saúde dos países membros da UNASUL.

A metodologia aqui utilizada foi idêntica à empregada na análise do PECS/CPLP, qual seja a análise da situação atual de implementação do Plano Quinquenal, bem como os projetos de cooperação que foram firmados entre os países membros, cujo objeto resida, especificamente, no incremento da atenção primária à saúde.

No que tange à Área de Trabalho Desenvolvimento e Gestão de Recursos Humanos em Saúde, a qual vem sendo coordenada pelo Brasil e pelo Peru, o Brasil introduziu a idéia de desenvolvimento das instituições estruturantes dos sistemas de saúde (Institutos Nacionais de Saúde, Escolas de Saúde Pública e Escolas Técnicas de Saúde), sendo que, destas três instituições, a única que ainda se encontra em fase de organização são as Escolas de Saúde Públicas.

Ainda nesta Área de Trabalho, outra iniciativa reside na criação do Instituto Sul Americano de Governo em Saúde (ISAGS), a qual vem sendo conduzida pela FIOCRUZ, sendo que o Estatuto da ISAGS já foi, inclusive, aprovado pelo Conselho de Ministros da UNASUL.

Na Área de Trabalho Promoção da Saúde e Ação sobre os determinantes da Saúde, já foi elaborado um Plano de Trabalho, o qual não contempla nenhum projeto 
que tenha como objeto específico o incremento da atenção primária à saúde dos países membros da UNASUL.

E, por fim, no que tange à Área de Trabalho Desenvolvimento dos Sistemas de Saúde Universais, após o início da vigência do Plano Quinquenal vem sendo desenvolvido um projeto de cooperação entre a FIOCRUZ e o Paraguai, cujo objeto reside na adoção, pelo Estado paraguaio, do modelo de atenção primária à saúde brasileira, o qual se encontra em andamento.

Desta forma, apesar da pouca vigência do Plano Quinquenal, constata-se que a Área de Trabalho Desenvolvimento e Gestão de Recursos Humanos em Saúde tem sido a mais privilegiada, uma vez que a criação do ISAGS foi elencada como sendo uma prioridade para a UNASUL Saúde.

E assim, lamentavelmente, o Plano Quinquenal, no que tange ao incremento da atenção primária à saúde dos sistemas de saúde seus países membros, vem revelando-se como sendo um instrumento de pouca efetividade, o que pode ser comprovado pela ausência de projetos de cooperação firmados após a sua vigência cujo objeto resida no incremento da atenção primária de seus países membros, circunstância esta, inclusive, que pode estar umbilicalmente ligada ao forte caráter programático deste Plano. 


\section{6 - CONCLUSÃO}

Com efeito, a iniciativa da Comunidade de Países de Língua Portuguesa (CPLP), bem como da União de Nações Sul-Americanas (UNASUL) de instituírem, cada qual, órgãos setoriais responsáveis pela elaboração de Planos (bem como de políticas) a serem implementadas no campo da saúde (CPLP Saúde e UNASUL Saúde) é digna dos mais renomados aplausos, na medida em que ambos os blocos reconhecem a importância (e a relevância) da execução de políticas públicas de saúde destinadas a assegurar às suas populações a oferta de ações e serviços de saúde de qualidade.

Os dois supracitados blocos congregam como membros, em sua grande maioria, países em desenvolvimento, os quais, via de regra, ainda revelam inúmeras deficiências em seus sistemas públicos de saúde, contexto no qual a cooperação sulsul em matéria de saúde revela-se fundamental, uma vez que, por ser realizada entre países com uma certa simetria no que tange ao nível de desenvolvimento (bem como em relação ao idioma e às condições sócio-culturais), possui uma maior chance de alcançar resultados positivos no que tange ao aperfeiçoamento dos sistemas de saúde envolvidos.

Ambos os blocos regionais possuem como nítido objetivo assegurar às populações envolvidas a adoção de sistemas públicos de acesso universal, contexto no qual, como já demonstrado, a oferta de serviços de Atenção Primária à Saúde (APS) de qualidade revela-se essencial.

Isso porque inúmeros estudos realizados já constataram o fato de que a orientação dos sistemas nacionais de saúde pelos princípios da atenção primária encontra-se diretamente ligada à melhoria de resultados alcançados, circunstância esta que levou a Organização Pan-Americana da Saúde (OPAS) a reafirmar, em 
2005, que basear os sistemas de saúde na APS é a melhor abordagem para produzir melhoras sustentáveis e equitativas na saúde das populações das Américas ${ }^{19}$.

Especificamente em relação aos países membros da CPLP e da UNASUL com uma significativa percentagem da população domiciliada em áreas rurais, o incremento da APS se revela ainda mais necessário, uma vez que estas populações necessitam sobremaneira de cuidados básicos de saúde, o que, caso executado a contento, evitaria o seu deslocamento aos grandes centros urbanos, situação que sobrecarrega ainda mais as atenções secundárias e terciárias à saúde.

Neste contexto, tanto o Plano de Cooperação instituído no âmbito da CPLP (o PECS/CPLP), como o Plano Quinquenal de Saúde da UNASUL reconhecem a importância da oferta de serviços de Atenção Primária à Saúde de qualidade aos usuários dos sistemas de saúde de seus países membros.

Visando alcançar tais resultados, ambos os Planos prevêem, como condição indispensável para que isto venha a ocorrer, a necessidade de qualificação dos recursos humanos em saúde, instituindo uma série de atividades a serem realizadas neste setor, tais como, no âmbito da CPLP, a estruturação da Rede de Escolas Técnicas em Saúde da CPLP, da Rede de Escolas Nacionais de Saúde Pública da CPLP e a Formação Médica Especializada nos Países de Língua Portuguesa, bem como, no âmbito da UNASUL, a criação do Instituto Sul-Americano de Governo em Saúde (ISAGS), por intermédio do qual serão ofertados seminários, cursos e outras iniciativas visando o aperfeiçoamento dos profissionais de saúde de seus países membros.

Entretanto, no que tange ao aperfeiçoamento da oferta de serviços de Atenção Primária à Saúde (APS) propriamente dita, percebe-se que o Plano instituído no âmbito da CPLP revelou-se mais apto a produzir resultados mais eficientes, uma vez que, reconhecendo e levando em conta as características dos sistemas de saúde de seus países, prevê medidas concretas para o seu incremento (a implantação das Comunidades Saudáveis, de um Programa de sensibilização de curandeiros, bruxos e

\footnotetext{
${ }^{19}$ Tal afirmação encontra-se inserida na Renovação da Atenção Primária em Saúde nas Américas, de 2005, disponível em <http://www.paho.org/portuguese/ad/ths/os/phc2ppaper_10-ago05_Por.pdf>. Acesso em 06/03/2011.
} 
demais médicos e parteiras tradicionais, bem como o desenvolvimento de estudos destinados ao enfrentamento das determinantes sociais da saúde), as quais, caso implementadas, poderão representar uma melhora sensível na campo da APS dos sistemas de saúde de seus Estados membros.

Tal circunstância, inclusive, pode ser comprovada no plano fático pela constatação de que, desde o início da vigência do PECS/CPLP, já foram firmados diversos projetos de cooperação entre o Brasil e os Países membros da CPLP, diretamente focados no incremento da atenção primária à saúde.

Ao contrário, o Plano Quinquenal da UNSAUL, na área de trabalho relativa ao Desenvolvimento de Sistemas de Saúde Universais, limita-se a impor como resultado a ser alcançado "melhorar a equidade e o acesso dos sistemas de saúde universais e integrais", através da "promoção da formação de redes integrais de serviços de saúde, baseadas na APS”. No entanto, o Plano é falho por não dispor, imediatamente, como se operacionalizará tal propósito, razão pela qual espera-se que, por ocasião de sua revisão em maio de 2013, sejam adotadas medidas mais concretas para o fortalecimento da APS nos sistemas de saúde de seus Estados membros.

E, corroborando o afirmado acima, deve ser ressaltada a circunstância de que, desde o início da vigência do Plano Quinquenal da UNASUL, nenhum projeto de cooperação cujo objeto resida especificamente na questão do incremento da atenção primária à saúde foi firmado, fato este que se encontra umbilicalmente ligado ao seu caráter essencialmente programático. 


\section{REFERÊNCIAS BIBLIOGRÁFICAS}

AITH, Fernando. Curso de Direito Sanitário. São Paulo: Editora Quartier Latin, 2007. 406 p.

ALMEIDA, Célia; CAMPOS, Rodrigo Pires de; BUSS, Paulo; FERREIRA, José Roberto; FONSECA, Luiz Eduardo. A concepção brasileira de “cooperação sul-sul estruturante em saúde”. RECIIS - Revista Eletr. de Com. Inf. Nov. Sáude, Rio de Janeiro, v. 4, n. 1, março de 2010. p. 25-35.

BRASIL. Constituição Federal. 1988.

Portaria GM/MS n 648, de 28 de março de 2006 - Aprova a Política Nacional de Atenção Básica (PNAB).

MINISTÉRIO DA SAÚDE. O SUS de A a Z : Garantindo Saúde nos Municípios. Brasília: Editora do Ministério da Saúde, 2009. 477 p.

BULARD, Martine. Os Sistemas de Saúde no mundo. In: Le Monde Diplomatique Brasil. Fevereiro de 2010. Disponível em $<$ http://www.diplomatique.org.br/print.php?tipo=ar\&id=629>. Acesso em 26/03/2010.

BUSS, Paulo Marchiori. A UNASUL Saúde. In: Le Monde Diplomatique Brasil. Setembro de 2009. Disponível em < http://diplomatique.uol.com.br/artigo.php?id=557\&PHPSESSID=1c600c9cdba67244 676ea7f7398227ad>. Acesso em 23/11/2010. 
BUSS, Paulo Marchiori; LEAL, Maria do Carmo. Saúde global e diplomacia da saúde. Cad. Saúde Pública, Rio de Janeiro, v. 25, n. 12, dezembro de 2009. p. 25402541.

BUSS, Paulo Marchiori; FERREIRA, José Roberto. Ensaio crítico sobre a cooperação internacional em saúde. RECIIS - Revista Eletr. de Com. Inf. Inov. Saúde. Rio de Janeiro, v.4, n.1, março de 2010a. p. 93-105.

Diplomacia da Saúde e cooperação sul-sul : as experiências da UNASUL saúde e do Plano Estratégico de Cooperação em Saúde da Comunidade de Países de Língua Portuguesa (CPLP). RECIIS - Revista Eletr. de Com. Inf. Nov. Sáude, Rio de Janeiro, v. 4, n. 1, março de 2010b. p. 106-118.

CARVALHO, Cristiano; MACHADO, Rafael Bicca; TIMM, Luciano Benetti. Direito Sanitário Brasileiro. São Paulo: Editora Quartier Latin, 2004. 350 p.

CPLP. Plano Estratégico de Cooperação em Saúde da CPLP. 2009a. (PECS/CPLP 2009/2012). Disponível em <http://www.cplp.org>. Acesso em 04/03/2011.

—. Declaração do Estoril. 2009b. Disponível em http://www.cplp.org/Admin/Public/DWSDownload.aspx?File=\%2fFiles\%2fFiler\%2f cplp\%2fredes\%2fsaude\%2fIIReuniaoEstoril\%2fDeclarEstorilFINAL_15Maio.pdf. Acesso em 03/03/2011.

ESCOLA NACIONAL DE SAÚDE PÚBLICA. Ex-Presidente da FIOCRUZ destaca a importância do UNASUL Saúde para a América do Sul. Disponível em <htttp://www.ensp.fiocruz.br/portal-espn/informe>. Acesso em 23/11/2010. 
MORAES, Alexandre de. Direito Constitucional. 11 ${ }^{\mathrm{a}}$ edição. São Paulo: Editora Atlas, 2001. 836 p.

ORGANIZAÇÃO DAS NAÇÕES UNIDAS. Carta de São Francisco. 1945. Disponível em http://www.onu-brasil.org.br/doc1.php. Acesso em 02/03/2011.

PEREIRA, Cláudia Fernanda de Oliveira. Direito Sanitário : a relevância do controle nas ações e serviços de saúde. Belo Horizonte: Editora Fórum, 2004. 272 p.

PEREIRA, Maurício Gomes. Epidemiologia Teoria e Prática. $12^{\mathrm{a}}$ edição. Rio de Janeiro: Guanabara Koogan, 2008. 596 p.

PNUD BRASIL. Brasil é referência em cooperação sul-sul. Disponível em < http://www.pnud.org.br/administracao/reportagens/index.php?id01=3554\&lay=apu >. Acesso em 09/09/2010.

PNUD BRASIL. Cooperação Sul-Sul facilita o acesso a medicamentos essenciais e quebra de patentes. Disponível em $<$ http://www.ipcundp.org/pressroom/pdf/IPCPressroom273.pdf>. Acesso em 02/09/2010.

RODRIGUES, Paulo Henrique; SANTOS, Isabela Soares. Saúde e Cidadania : uma visão histórica e comparada do SUS. São Paulo: Editora Atheneu, 2009. 165 p.

SANTANA, José Paranaguá de. Um olhar sobre a cooperação sul-sul em saúde. Trabalho desenvolvido associadamente ao projeto de doutorado do autor em Ciências da Saúde junto à UNB. Disponível em < 
http://www.cienciaesaudecoletiva.com.br/artigos/artigo_int.php?id_artigo=5255>. Acesso em 28/10/2010.

SECRETARIA-GERAL IBERO-AMERICANA. Informe da Cooperação sul-sul na Ibero-América 2009. Disponível em $<$ http://iberoamericaporhaiti.com/index.php/pt/component/content/article/59.html>. Acesso em 02/09/2010.

SEGRE, Marco; FERRAZ, Flávio Carvalho. O conceito de saúde. Rev. Saúde Pública, São Paulo, v. 31, n. 5, Outubro de 1997. p. 538-542.

SILVESTRE, Rosa Maria. A horizontalização da cooperação técnica internacional : o caso das funções essenciais de saúde pública no Brasil. Dissertação de Mestrado. Universidade de Brasília, março de 2007.

UNASUL. Plano Qüinqüenal de Saúde da UNASUL (2010-2015). Disponível em $<$ http://www.pptunasur.com>. Acesso em 04/03/2011 